\title{
Risk transfer beyond reinsurance: the added value of CAT bonds
}

\author{
Tobias Götze ${ }^{1} \cdot$ Marc Gürtler $^{1}$
}

Received: 15 July 2020 / Accepted: 27 April 2021 / Published online: 31 May 2021

(C) The Author(s) 2021

\begin{abstract}
Reinsurance and CAT bonds are two alternative risk management instruments used by insurance companies. Insurers should be indifferent between the two instruments in a perfect capital market. However, the theoretical literature suggests that insured risk characteristics and market imperfections may influence the effectiveness and efficiency of reinsurance relative to CAT bonds. CAT bonds may add value to insurers' risk management strategies and may therefore substitute for reinsurance. Our study is the first to empirically analyse if and under what circumstances CAT bonds can substitute for traditional reinsurance. Our analysis of a comprehensive data set comprising U.S. P\&C insurers' financial statements and CAT bond use shows that insurance companies' choice of risk management instruments is not arbitrary. We find that the added value of CAT bonds mainly stems from non-indemnity bonds and reveal that (non-indemnity) CAT bonds are valuable under high reinsurer default risk, low basis risk and in high-risk layers.
\end{abstract}

Keywords CAT Bond $\cdot$ Reinsurance $\cdot$ Risk management

\section{Introduction}

Reinsurance and CAT bonds are two alternative instruments used for risk management by insurance companies. Reinsurance is the most frequently used of the two instruments. Over the last 20 years, however, CAT bonds have gained a significant market share. The well-established result obtained by Modigliani and Miller (1958) implies that, in a perfect capital market, companies should be indifferent between different risk management instruments and might even forego any

Marc Gürtler

marc.guertler@tu-bs.de

Tobias Götze

t.goetze@tu-bs.de

1 Braunschweig Institute of Technology, Department of Finance, Abt-Jerusalem-Straße 7, 38106 Brunswick, Germany 
risk management activities. However, the theoretical literature on reinsurance and CAT bonds conjectures that reinsurer default risk, the insured risk layer, basis risk and information asymmetries determine how the two instruments are used (Doherty and Richter 2002; Nell and Richter 2004; Cummins and Trainar 2009; Finken and Laux 2009; Lakdawalla and Zanjani 2012; Trottier and Lai 2017; Subramanian and Wang 2018). These theoretical results have not been verified empirically, which is surprising given their important implications for the re/ insurance market. Therefore, the goal of the present study is to examine insurers' choices between CAT bonds and reinsurance and to empirically determine the situations in which CAT bonds are used as substitutes for reinsurance.

To accomplish this goal, we derive empirically testable hypotheses on the determinants of substitution between reinsurance and CAT bonds from the theoretical literature. To test these hypotheses, we use a comprehensive data set based on U.S. P\&C insurers' annual reports to the National Association of Insurance Commissioners (NAIC), reinsurer rating data from Standard \& Poor's (S\&P) and AM Best, and information on insurers' use of CAT bonds. Based on that data set, CAT bond use is measured using the premium volume of issued CAT bonds and proxy variables are established to examine the determinants of substitution between reinsurance and CAT bonds. Namely, we use the average reinsurer rating as a proxy for reinsurer default risk, the CAT bond's expected loss as a proxy for the insured risk layer, insurers' geographical concentration as a proxy for basis risk, and the (in)sustainability of insurers' reinsurance relationships as a proxy for information asymmetries. Next, we conduct different types of panel regressions to measure the relationship between reinsurance use and CAT bond use in dependence of the above-mentioned factors.

We observe a significant substitution effect between reinsurance and CAT bonds that stems mainly from non-indemnity bonds and suggests that CAT bonds provide added value to reinsurers', risk management strategies. Consistent with theoretical evidence, our analyses indicate that the added value of CAT bonds is more pronounced for insurers that face high reinsurer default risk. Our study also shows that non-indemnity CAT bonds are rather used as substitutes for reinsurance in high-risk layers and by insurers with low exposure to basis risk. Although the theoretical literature suggests that CAT bonds should be used to compensate information asymmetries, our evidence in that regard is ambiguous.

This study is the first to explain why insurance companies pursue different risk management strategies and use both reinsurance and CAT bonds to manage their underwriting risks. By analysing the factors influencing insurers' use of CAT bonds and traditional reinsurance, we offer insights into the formation of corporate risk management strategies in the insurance industry. From an insurance industry perspective, the contribution of our results is threefold. First, our results potentially provide insights to insurance companies that may better understand the formation of risk management strategies among their peers. Second, our results are relevant for reinsurers and CAT bond investors as they contribute to explaining why insurers use certain risk management instruments. Third, our results are valuable from a regulator perspective, as they identify the factors motivating insurers to diversify and potentially extend their toolbox of risk 
management instruments. This understanding of the conditions under which CAT bonds can substitute traditional reinsurance and add value to insurers' risk management strategies is highly relevant. Based on the evidence presented by Froot et al. (1993) and Froot (2001), insurers purchase relatively few reinsurance against extreme catastrophic events at prices considerably above the fair price. Although such protection should theoretically have a very high value for corporate risk management strategies, anecdotal evidence also shows that the most severe natural catastrophes observed throughout the past years exhibit a considerable share of uninsured damages (Bevere et al. 2019), indicating that reinsurance markets may be subject to a shortage of supply of catastrophe risk transfer. From a regulator perspective, overcoming such supply shortages is important in order to facilitate market-based protection against catastrophic events. Throughout the past 20 years, CAT bonds have been one of the most successful instruments to overcome capacity shortages for catastrophe risk transfer (Cummins and Trainar 2009). Yet, reinsurance is still by far the dominant risk transfer instrument. ${ }^{1}$

The remainder of this paper is structured as follows. The "Background, literature review, and hypotheses" section gives background information on structural differences between reinsurance and CAT bonds, reviews the literature related to our study and derives the hypotheses to be tested in the empirical analysis. The "Data" section reviews the data set employed in the empirical analysis by describing the study's sample selection and variables and by presenting descriptive statistics. The "Empirical results" section conducts an empirical analysis. Finally, the "Conclusions" section concludes the paper.

\section{Background, literature review and hypotheses}

\section{Background}

Prior to examining the substitution of reinsurance by CAT bonds, this section explains the structural differences between reinsurance and CAT bonds that possibly lead to different patterns of use. The theoretical literature suggests that due to the differences between reinsurance and CAT bonds, the advantageousness of one or the other instrument will depend on the insurer and the insured risk (Doherty and Richter 2002; Nell and Richter 2004; Cummins and Trainar 2009; Cummins and Weiss 2009; Lakdawalla and Zanjani 2012; Trottier and Lai 2017; Subramanian and Wang 2018). Consequently, CAT bonds may sometimes add value to insurers' risk management and may therefore be used as a substitute for reinsurance.

CAT bonds are issued in the capital market, which has a significantly larger capacity to cope with extreme catastrophes than the reinsurance market and enables the diversification of risks that are not diversifiable through the reinsurance market

\footnotetext{
1 According to Standard and Poor's (2020), the global reinsurance capital was at USD 499 billion in the first quarter of 2020. In comparison, the outstanding capital in CAT bonds and other types of insurancelinked securities accounted for only USD 46 billion in 2020 (Artemis 2020).
} 
(Froot 2001; Doherty and Richter 2002; Nell and Richter 2004; Cummins and Trainar 2009; Cummins and Weiss 2009; Lakdawalla and Zanjani 2012; Subramanian and Wang 2018). Additionally, CAT bonds are fully collateralised and their capital is managed by a trustee, so that their sponsors are not exposed to the counterparty default risk a reinsurance contract carries (Froot 2001; Doherty and Richter 2002; Nell and Richter 2004; Cummins and Trainar 2009; Cummins and Weiss 2009; Lakdawalla and Zanjani 2012; Trottier and Lai 2017). These characteristics both make CAT bonds preferable to reinsurance as a way to cover high layers of risk (Cummins and Weiss 2009; Lakdawalla and Zanjani 2012; Trottier and Lai 2017; Subramanian and Wang 2018). The payout of CAT bonds may be defined either on an indemnity or non-indemnity basis, whereas reinsurance contracts are typically defined on an indemnity basis (Doherty and Richter 2002; Nell and Richter 2004; Cummins and Weiss 2009; Finken and Laux 2009). Non-indemnity payout triggers, which can be designed as parametric, loss index, modelled loss or hybrid triggers, are more advantageous than indemnity triggers in terms of information asymmetries and moral hazard because the sponsoring insurer cannot influence the bond's payout. However, non-indemnity CAT bonds exhibit basis risk, which arises because the payout structure may not be perfectly correlated with the insurer's actual losses (Doherty and Richter 2002; Cummins et al. 2004; Nell and Richter 2004; Cummins and Weiss 2009; Finken and Laux 2009; Braun 2016; Gürtler et al. 2016). Reinsurance is based on long-term contract relationships, and reinsurers exhibit underwriting resources superior to those of CAT bond investors, which mitigates moral hazard and adverse selection issues (Doherty and Richter 2002; Cummins and Trainar 2009; Finken and Laux 2009; Trottier and Lai 2017; Subramanian and Wang 2018). Furthermore, through reinsurance, collateral is provided more efficiently through the use of diversification (Lakdawalla and Zanjani 2012). Finally, unlike contracting a reinsurer, the issuance of a CAT bond incurs significant fixed costs resulting from the placement of the bond on the capital market and the involvement of third parties in the transaction (e.g. underwriter, risk modelling agent, trustee). These fixed costs prohibit the issuance of small-scale bonds and usually lead to the issuance of bonds over a multi-year period (Gürtler et al. 2016). ${ }^{2}$ The restricted scalability of CAT bonds impedes their use by small companies for risk management (Cummins and Trainar 2009).

After pointing out the differences between CAT bonds and reinsurance, the following section will provide an overview of the related literature.

\section{Literature review}

This study is related to three strands of the literature. The first comprises studies on reinsurance and the determinants of reinsurance use (Doherty and Schlesinger 1983; Ashby and Diacon 1998; Garven and Lamm-Tennant 2003; Bernard and Ludkovski 2012; Cai et al. 2013; Lin et al. 2015). The empirical evidence shows that varying

\footnotetext{
2 According to Braun (2016), Gürtler et al. (2016), and Götze and Gürtler (2020), the mean term of a CAT bond is three years.
} 
degrees of reinsurance use are related to factors such as uninsurable background risk (Doherty and Schlesinger 1983), counterparty risk (Bernard and Ludkovski 2012; Park et al. 2019), information asymmetries (Garven et al. 2014), strategic considerations (Ashby and Diacon 1998), contract design (Cai et al. 2013), market state (Cole and McCullough 2006), liquidity creation (Desjardins and Dionne 2017) and network structures (Lin et al. 2015; Chen et al. 2018).

The second literature strand comprises empirical literature on the factors influencing CAT bond use. Hagendorff et al. (2014) find that low-risk insurers have a higher propensity to issue CAT bonds. The authors conclude that high-risk insurers are charged higher premiums by the capital market based on publicly-observable risk measures, whereby CAT bonds are less attractive than reinsurance for this group of insurers. ${ }^{3}$ This assumption is confirmed by Götze and Gürtler (2020), who show that insurer characteristics influence the premiums of CAT bonds. Although Hagendorff et al. (2014) offer insights into the determinants of CAT bond issuance, they do not investigate the substitutional use of CAT bonds and reinsurance, which is the subject of our study.

The third literature strand provides theoretical evidence on the use of CAT bonds and reinsurance. Existing models are all based on the structural differences between CAT bonds and reinsurance discussed in the "Background" section. The models of Doherty and Richter (2002), Nell and Richter (2004) and Finken and Laux (2009) focus on the different payout triggers and assume that reinsurance is based on indemnity triggers, whereas CAT bonds are based on exogenous index or parametric triggers. Using a mean variance framework, Doherty and Richter (2002) show that the complementary use of an index-based CAT bond and indemnity-based gap insurance increases risk transfer efficiency depending on the transaction costs of the two instruments. Using an expected utility framework, Nell and Richter (2004) reveal that CAT bond use increases relative to reinsurance use depending on the basis risk, and that risk transfer via reinsurance shifts from higher to lower loss layers due to the availability of index CAT bonds. Finken and Laux (2009) indicate that access to CAT bonds with an exogenous payout trigger reduces cross-subsidisation between low- and high-risk insurers in the reinsurance market because low-risk insurers can use index-based CAT bonds as an alternative to reinsurance.

The partial equilibrium model of Lakdawalla and Zanjani (2012) focuses on the full collateralisation mechanism of CAT bonds, which is less efficient than reinsurance that relies on collateral access for all possible claimants. However, when the authors consider reinsurers' contracting constraints and frictional costs, they show that CAT bonds may be beneficial in some market segments (e.g. risks with limited diversification potential). The authors also find that CAT bonds are more likely to be employed by low-risk type insurers. Trottier and Lai (2017) use a contingent claims model to study the joint use of indemnity CAT bonds and reinsurance. In their model, reinsurance and CAT bonds differ in terms of their exposure to moral hazard,

\footnotetext{
3 According to Hagendorff et al. (2014), reinsurers are better than investors in the capital market at obtaining private information on an insurer. Therefore, the premiums charged by reinsurers are more closely aligned with the insurer's actual risk profile, making reinsurance more attractive than CAT bonds.
} 
which is greater for CAT bond investors than reinsurers, and reinsurer default risk, which is not present for CAT bonds. The authors find that a mix of reinsurance and CAT bonds enhances shareholder value and remains optimal, independent of the volatility of losses. Further findings show that reinsurance should be used for lower and CAT bonds for higher risk layers and that insurers with high exposure to catastrophe risk should use reinsurance. Subramanian and Wang (2018) study the use of reinsurance and CAT bonds for signaling purposes in an equilibrium framework in which the difference between the instruments is based on reinsurers' superior ability to identify an insurer's risk, which eliminates adverse selection. Similar to Trottier and Lai (2017), they conclude that reinsurance is advantageous for lower layers of risk and CAT bonds for higher layers. Additionally, a high exposure to catastrophic risks leads fewer insurers to choose CAT bonds over reinsurance or retention.

The theoretical work shows that the value CAT bonds add to insurers' risk management strategies seems to consist of (1) eliminating reinsurer default risk, (2) providing a better risk diversification in high-risk layers, where the diversification benefits of reinsurance deteriorate, (3) introducing non-indemnity-based contracts that include basis risk and that may be attractive for insurers with a relatively low exposure to basis risk, and (4) reducing information asymmetry between insurers and reinsurers through non-indemnity-based contracts (Doherty and Richter 2002; Nell and Richter 2004; Cummins and Trainar 2009; Finken and Laux 2009; Lakdawalla and Zanjani 2012; Trottier and Lai 2017; Subramanian and Wang 2018). An empirical examination of these theoretical results will allow us to assess which of the above aspects actually causes the substitution of reinsurance by CAT bonds. Therefore, we will consider these theoretical insights below, and derive our hypotheses for the empirical analysis.

\section{Hypotheses}

The theoretical findings on CAT bond and reinsurance use indicate that insurers have various incentives for substituting reinsurance with CAT bonds. To be attractive as an alternative to reinsurance, CAT bonds have to add value to insurers' risk management strategies through more efficient or more effective risk transfer. Consequently, our hypothesis development is based on those aspects of insurer's risk management strategies that can be improved through the availability of CAT bonds.

A challenge that arises in risk transfer via reinsurance is default risk. In a reinsurance relationship, insurers are exposed to the default risk of their reinsurers, who may not be able to comply with their contractual obligations under all states of the future (Lakdawalla and Zanjani 2012; Park et al. 2019). In a CAT bond transaction, insurance coverage is fully collateralised via a special-purpose vehicle. Therefore, insurers' exposure to default risk is significantly reduced (Doherty and Richter 2002; Nell and Richter 2004; Cummins and Trainar 2009; Lakdawalla and Zanjani 2012; Trottier and Lai 2017; Subramanian and Wang 2018). However, even in this structure, default risk is not completely eliminated. Prior to the financial crisis, CAT bond transactions frequently included a total return swap to protect the collateral against changes in interest rates. The investment bank Lehman Brothers acted as 
swap counterparty in four CAT bonds and, consequently, its bankruptcy in 2008 also led to the default of those bonds (Cummins and Weiss 2009; Carayannopoulos and Perez 2015; Braun 2016; Gürtler et al. 2016). ${ }^{4}$ After that incident, the total return swap basically disappeared from the CAT bond market and the arrangements for collateral investments were tightened (Braun 2016). Altogether, CAT bonds therefore seem to exhibit a smaller exposure to counterparty default risk in comparison to reinsurance. Thus, CAT bonds may add value to insurers' risk management strategies by eliminating or reducing the exposure to reinsurer default risk. Consequently, the substitution of CAT bonds for reinsurance may be reasonable for insurers with a high exposure to reinsurer default risk. A study by Park et al. (2019) shows that a reinsurer's financial strength rating is a suitable proxy for its default risk and that a reinsurer downgrade causes insurers to cede less business to that reinsurer. Therefore, we assume that the average rating of an insurer's reinsurance counterparties can be used as a measure for its exposure to default risk and we hypothesise the following:

Reinsurer default risk hypothesis (H1) Insurers whose reinsurance counterparties exhibit a weaker average rating replace reinsurance with CAT bonds.

Another aspect that may influence the choice between reinsurance and CAT bonds is the insured risk layer. In lower risk layers, reinsurance is a well-established risk management instrument, and reinsurers can effectively diversify primary insurers' losses, resulting in relatively low costs compared to the significant issuance costs of CAT bonds (Cummins and Trainar 2009). For the extremely high losses insured in the highest risk layers, reinsurance becomes very costly because reinsurers can no longer diversify the losses effectively (Cummins and Trainar 2009). Therefore, insurers purchase relatively little reinsurance against extreme loss events; when they do, they have to pay high price markups (Froot 2001). In this context, the utility of CAT bonds consists of exploiting the capacity of the capital market, which exhibits a significantly larger loss-bearing capacity than the reinsurance market (Cummins and Trainar 2009). Consequently, CAT bonds' relative cost efficiency compared to reinsurance increases as the risk layer increases, and CAT bonds should thus be a valuable alternative to reinsurance in high-risk layers (Nell and Richter 2004; Lakdawalla and Zanjani 2012; Trottier and Lai 2017; Subramanian and Wang 2018). Consequently, we hypothesise the following:

Risk layer hypothesis ( $\mathrm{H} 2)$ Insurers use CAT bonds as a substitute for reinsurance in high-risk layers.

\footnotetext{
${ }^{4}$ Only one of those four bonds, Willow Re B of the sponsor Allstate, is included in our sample. We test whether that bond influences our results in a robustness check by including a dummy variable for observations related with Willow Re B. The results of that robustness check are in line with the results from our main analysis and are presented in Section E of the Online Appendix.
} 
Basis risk poses a challenge to the use of many risk transfer instruments because it reduces their loss-hedging effectiveness. The reinsurance market handles basis risk by contractually determining payouts on an indemnity basis, that means, based on the actual losses incurred by the insurer. Thus, basis risk is essentially eliminated. However, the elimination of basis risk comes at a cost because indemnity-based contracts create information asymmetries, which increase the costs of risk transfer (Finken and Laux 2009). Some insurers may be unwilling to accept the additional costs of indemnity-based contracts and seek alternative ways to transfer their risks. In that case, CAT bonds may add value to insurers' risk management because their payout can also be triggered on a non-indemnity basis, which significantly reduces information asymmetries (Doherty and Richter 2002; Cummins et al. 2004; Nell and Richter 2004; Cummins and Weiss 2009; Finken and Laux 2009). A downside of non-indemnity CAT bonds is their exposure to basis risk, which means that they may be a suitable alternative to indemnity-based reinsurance only for insurers with a limited exposure to basis risk (Doherty 1997; Doherty and Richter 2002; Cummins et al. 2004; Nell and Richter 2004; Cummins and Weiss 2009). Such insurers can be expected to replace some of their reinsurance with non-indemnity CAT bonds because this will reduce the costs of risk transfer induced by information asymmetries at an acceptable level of basis risk. Insurers whose underwriting risk is highly idiosyncratic (e.g. because they are concentrated in a particular market segment) and who thus have a high exposure to basis risk may not regard CAT bonds with a non-indemnity trigger as a perfect substitute for reinsurance (Doherty 1997; Doherty and Richter 2002; Cummins et al. 2004; Nell and Richter 2004; Cummins and Weiss 2009). This assumption is confirmed by the models of Doherty and Richter (2002) and Nell and Richter (2004). Cummins et al. (2004) indicate that basis risk is a problem for insurers with a geographically-concentrated business and is limited for insurers with a sufficient degree of geographical diversification. Consequently, our hypothesis on how basis risk influences the substitution of reinsurance by non-indemnity CAT bonds is as follows:

Basis risk hypothesis (H3) Geographically-diversified insurers (i.e. insurers with less exposure to basis risk) replace reinsurance with non-indemnity CAT bonds.

As mentioned in the context of basis risk, insurers should consider the information costs induced by the use of risk transfer instruments due to information asymmetries. In this context, non-indemnity CAT bonds may add value to insurers' risk management strategies by significantly reducing information costs. To reduce information asymmetries, reinsurers acquire both public and private information on the insurer, from which they assume risk (Hagendorff et al. 2014). For this reason, insurers and reinsurers often maintain their contract relationships on a longterm basis because, in that way, reinsurers can increase their private information on the insurer (Jean-Baptiste and Santomero 2000; Finken and Laux 2009; Garven et al. 2014). This improved private information decreases information asymmetries between the reinsurer and insurer regarding the actual risk being incurred (JeanBaptiste and Santomero 2000; Garven et al. 2014). Consequently, the reinsurer may 
be able to decrease the risk premium charged from the insurer, in turn enabling the insurer to purchase reinsurance more efficiently (Jean-Baptiste and Santomero 2000; Garven et al. 2014). Based on this argument, reinsurance should be more attractive than CAT bonds in the presence of long-term reinsurance contract relationships. However, insurers that cannot establish long-term contract relationships with their reinsurers may be charged higher premiums due to the higher information asymmetries (Finken and Laux 2009). In that case, non-indemnity CAT bonds provide a way to circumvent high information asymmetries because their exogenous trigger mechanism does not require CAT bond investors to obtain private information on the insurer's risk (Finken and Laux 2009). Thus, non-indemnity bonds may be attractive when the reinsurance relationship is characterised by information asymmetries. Therefore, we assume that, in the absence of long-term reinsurance relationships, insurers may use non-indemnity CAT bonds to overcome information asymmetries. We thus hypothesise as follows:

Asymmetric information hypothesis (H4) Insurers with fewer long-term reinsurance relationships (i.e. higher information asymmetries) replace reinsurance with nonindemnity CAT bonds.

In what follows, we describe the data set used to test the hypotheses.

\section{Data}

\section{Sample selection}

Our sample consists of insurers' financial statements reported to the NAIC between 2004 and 2017. The data comprise information on the insurers' balance sheets, the regional distribution of their premiums and losses, and their reinsurance transactions. Additionally, to calculate our measure of default risk exposure, we obtain reinsurers' financial strength ratings from S\&P and AM Best over the same time period. The insurer- and reinsurer-specific data are supplemented by information on the CAT bonds sponsored by the respective insurers and active during the same period. The CAT bond data, provided by Lane Financial LLC, provide information on the bonds' issue volume, premium, expected loss (EL), term and sponsor. Data on the bonds' payout triggers are obtained from the Artemis Deal Directory and Aon Benfield.

We match the CAT bond data with the insurers' financial statement data by searching the CAT bond sponsors from the insurance companies/groups in the financial statement data set. We follow Chen et al. (2008) and Berry-Stölzle et al. (2012) in conducting our analysis at the group level because CAT bonds are usually issued at that level. Thus, we aggregate the financial statement data at the group level (except for independent single companies, which are not part of a group) because we assume that this is the level at which the risk management strategy is conducted. 
To prepare the data set for our empirical analysis, we first exclude all observations in which information required for the dependent or explanatory variables are missing. Second, we exclude all companies that are under some kind of regulatory supervision. Third, following Cummins et al. (2001), Powell and Sommer (2007), Berry-Stölzle et al. (2012) and Lin et al. (2015), we exclude companies with nonpositive values for total assets, policyholder surplus, premiums written, losses and loss adjustment expenses incurred, and reinsurance premiums ceded. ${ }^{5}$ Fourth, we exclude companies that report a reinsurance ratio (reinsurance premiums ceded to non-affiliates divided by the sum of reinsurance premiums assumed from non-affiliates and direct premiums written) above one because this indicates that the insurer cedes more risks than it assumes (Powell and Sommer 2007; Lin et al. 2015).

Our final data set after outliers are excluded comprises an unbalanced panel of 11,545 observations, where one observation corresponds to a combination of insurer and year.

\section{Variables}

We describe below the variables used in our empirical analysis.

\section{Dependent variable}

Our study examines how CAT bonds influence the use of reinsurance. Therefore, our dependent variable needs to be a proxy of reinsurance use. We use a measure that is common in the reinsurance literature and define the variable Reinsurance Ratio as the ratio between reinsurance premiums ceded and the sum of the direct premiums written and reinsurance premiums assumed (Mayers and Smith 1990; Choi and Weiss 2005; Cole and McCullough 2006; Wang et al. 2008; Shiu 2011; Lee and Lee 2012; Garven et al. 2014; Lin et al. 2015; Yanase and Limpaphayom 2017; Altuntas et al. 2018).

\section{Main explanatory variables}

To examine whether insurers replace reinsurance with CAT bonds, we need to establish a measure of CAT bond utilisation. To that end, we calculate a measure that is defined as the ratio between the premiums ceded via CAT bonds and the sum of the direct premiums written and reinsurance premiums assumed. We denote this variable, defined in Equation (1), as the CAT Bond Ratio: ${ }^{6}$

\footnotetext{
${ }^{5}$ Observations with the above-mentioned parameter values need to be excluded, because they represent outliers in terms of the variables that we construct based on those values.

${ }^{6}$ In a robustness check, we alternatively calculate the CAT Bond Ratio and the subsequently introduced variables measuring CAT bond use, based on the bonds' ELs instead of the bonds' premiums. The results of this robustness check, which support the results of our main analysis, are presented in Section A of the Online Appendix.
} 


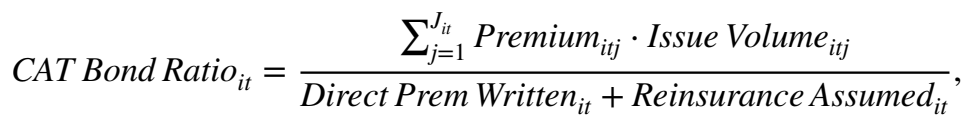

where $i=1, \ldots, I$ indicates the insurers in our sample, $t=1, \ldots, T$ refers to years in the sample period, and $j=1, \ldots J_{i t}$ refers to the outstanding CAT bonds of insurer $i$ in year $t$.

In 'Introduction' and 'Background, literature review, and hypotheses' sections, we described the difference between indemnity and non-indemnity CAT bonds and discussed their relevance with respect to basis risk (H3) and information asymmetries (H4). To test the differences between the two trigger types, we define two additional variables in the spirit of Equation (1), where we separately consider indemnity and non-indemnity bonds in the numerator. The variable Indemnity CAT Bond Ratio is as follows:

$$
\text { Indemnity CAT Bond Ratio }_{i t}=\frac{\sum_{k=1}^{K_{i t}} \text { Premium }_{i t k} \cdot \text { Issue Volume }_{i t k}}{\text { Direct Prem } \text { Written }_{i t}+\text { Reins Assumed }_{i t}},
$$

where $i=1, \ldots, I$ indicates the insurers in our sample, $t=1, \ldots, T$ refers to years in the sample period, and $k=1, \ldots K_{i t}$ (with $K_{i t} \leqslant J_{i t}$ ) refers to the outstanding CAT bonds with an indemnity trigger of insurer $i$ in year $t$. The definition of Non-Indemnity CAT Bond Ratio, reflecting the use of non-indemnity CAT bonds, is analogous.

In the risk layer hypothesis $(\mathrm{H} 2)$, we expect a substitution between reinsurance and CAT bonds to occur in high-risk layers. To test this hypothesis, we divide our main explanatory variables, Indemnity CAT Bond Ratio and Non-Indemnity CAT Bond Ratio, into two categories proxying for a high- and a low-risk layer based on the CAT bonds' ELs. Formally, this is expressed by the following equation for the Indemnity CAT Bond Ratio: ${ }^{7}$

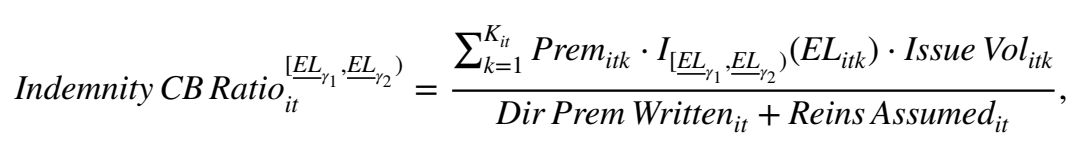

where $E L_{i t k}$ is the EL of bond $k$ of insurer $i$, and $E L_{\gamma_{1}}$ and $\underline{E L}_{\gamma_{2}}$ represent the upper and lower thresholds applied for the EL, respectively, to separate high- and low-risk layers. We use $\underline{E L_{\gamma_{1}}}=0 \%$ and $\frac{E L_{\gamma_{2}}}{8}=2 \%$ for high-risk layers, and $\underline{E L_{\gamma_{1}}}=2 \%$ and $\underline{E L}_{\gamma_{2}}=100 \%$ for low-risk layers. ${ }^{8}$

An insurer's decision to use a CAT bond and to transfer a certain share of risk via reinsurance are likely determined contemporaneously. Therefore, we follow the strategy of Lin et al. (2015) and include the CAT bond-related variables with a

\footnotetext{
${ }^{7}$ We use the following definition of an indicator function: $I_{M}(x)= \begin{cases}1 & \text { if } x \in M, \\ 0 & \text { otherwise. }\end{cases}$

${ }^{8}$ In a robustness check, which is presented in Section B of the Online Appendix, we conduct upward and downward shifts of the thresholds applied in the analysis of the risk layer hypothesis (H2). Our results are robust to the tested modifications of these thresholds.
} 
one-period lag (i.e. one year before the reinsurance decision is made) to measure the causal effect of CAT bond use on reinsurance use.

In the reinsurer default risk hypothesis (H1), we consider the possibility that insurers with a high exposure to the default of their reinsurance counterparties replace reinsurance with CAT bonds. We use reinsurer financial strength ratings of the rating agencies $\mathrm{S} \& \mathrm{P}$ and $\mathrm{AM}$ Best to measure that exposure. Therefore, we first match the ratings to the reinsurers in our sample. ${ }^{9}$ Second, we convert reinsurer ratings to a point scale. ${ }^{10}$ Third, we summarise the S\&P and AM Best ratings for the purpose of our analysis by always considering the better of the two ratings (for cases where a reinsurer is rated by both agencies). Fourth, we weight the point scale ratings with the premium ceded to the respective reinsurer and then calculate the average reinsurer rating for all the insurers in our sample. The resulting average is the variable Average Reinsurer Rating, which we use to test the reinsurer default risk hypothesis (H1).

To consider the potential influence of missing rating information, we include a variable Missing Rating Information, which equals the share of premiums ceded to reinsurers with no identified rating in our analysis. The basis risk hypothesis (H3), suggests that non-indemnity CAT bonds may be a suitable risk transfer instrument for insurers with a lower exposure to basis risk. To test this hypothesis, we examine the geographical concentration of the insurers in our sample. Our measure of geographical concentration, Geographic HHI, is based on the Herfindahl-Hirschman index and characterises the extent to which a company's business is concentrated in federal states (Cummins and Nini 2002; Choi and Weiss 2005; Cole and McCullough 2006; Cole et al. 2007; Garven et al. 2014; Lin et al. 2015; Biener et al. 2016; Mankaï and Belgacem 2016; Park et al. 2019). ${ }^{11}$

According to the asymmetric information hypothesis (H4), non-indemnity CAT bonds substitute for reinsurance if the relationship between the insurer and reinsurer is characterised by a high degree of asymmetric information, which is the case among insurers with fewer long-term reinsurance relationships. To test this hypothesis, we define Reinsurance Sustainability Index as the ratio of premiums ceded over a three-year period to reinsurers that are present in all these three years to the overall premiums ceded over the three-year period (Garven et al. 2014; Lin et al. 2015).

\footnotetext{
9 As the reinsurer rating data have to be merged manually to the financial statement information, we focus on reinsurers with a certain minimum market participation, that means, reinsurers that exhibit an annual premium volume of at least USD 8 million. We consider missing rating information through a control variable.

10 For example, for S\&P a rating of 'AAA' corresponds to a value of 1 on the point scale, a rating of 'AA+' to a value of 2 , and so on. The conversion is analogous for AM Best ratings.

11 In a robustness check that is documented in Section $\mathrm{C}$ of the Online Appendix, we test if the basis risk hypothesis (H3) also holds with an alternative measure of basis risk: the deviation of an insurer's CAT exposure from the overall market's CAT exposure. This robustness check confirms our result obtained with the variable Geographic HHI.
} 


\section{Control variables}

In the following, we introduce a series of control variables used to consider the known factors that can influence reinsurance demand. For concision, the variables and their definitions are summarised in Table 1. We use the variables Outdegree Constraint and Outdegree to model the cohesion and centrality of insurers in their reinsurance network. The variable CAT Exposure measures an insurer's exposure to natural catastrophes. The effect of company size is modelled by the variable $\log$ (Total Assets). The distribution of business over different lines is considered by the variable HHI Line. The four variables Short-tail Commercial Business, Longtail Commercial Business, Short-tail Personal Business and Long-tail Personal Business control for an insurer's business distribution. An insurer's profitability is modelled by introducing the variable Return on Assets (ROA). The need for a company to engage in risk management activities arises from its risky business activity. We introduce three variables to incorporate business risk in our models. First, we measure leverage as the ratio of liabilities to total assets and denote it as Liabilities to Total Assets. Second, we measure the volatility of cash flows by the variable Cash-Flow Volatility. Third, we define Liquidity Creation Ratio, which measures an insurer's tendency to create liquidity (i.e. to transform liquid liabilities into illiquid assets). Additionally, we consider the development of liabilities over time using the variable Liability Growth Rate. An insurer's age is modelled by the variable $\log ($ Age $)$. The two dummy variables Mutual and Stock control for an insurer's organisational form. The variables Net Premium to Surplus Ratio and Adjusted Liabilities to Liquid Assets measure if an insurer is under financial distress. Finally, the variable Price Regulation measures the share of business conducted in price regulated lines.

\section{Descriptive statistics}

Table 2 presents descriptive statistics on the variables used in our analysis. The insurers in our sample exhibit a mean Reinsurance Ratio of $24.2 \%$.

The relatively small mean of $0.008 \%$ of the CAT Bond Ratio indicates that most insurers in our sample do not use CAT bonds for risk transfer. However, the maximum of $8.3 \%$ indicates that some insurers transfer a substantial share of their risks to the CAT bond market. With a mean value of $0.003 \%$, the average insurer transfers slightly less risk with non-indemnity bonds than indemnity bonds (mean: $0.005 \%$ ). The Average Reinsurer Rating is at 2.6, which corresponds to the S\&P category 'AA' and the AM Best category 'A'. The mean of Missing Rating Information of 0.202 indicates that, on average, for $20 \%$ of the ceded premium, the reinsurer is either not rated or the rating is unknown. Geographic HHI has a mean of 0.61 . The mean of Reinsurance Sustainability Index is 0.694, which indicates that around $70 \%$ of the reinsurance relationships in our sample are long term.

The variable Outdegree Constraint has a mean value of 0.057 . The variable Outdegree has a mean of 0.003 . The mean CAT Exposure is at $10 \%$ and the deviation of CAT exposure from the market's exposure exhibits a mean of 0.502 . The average 


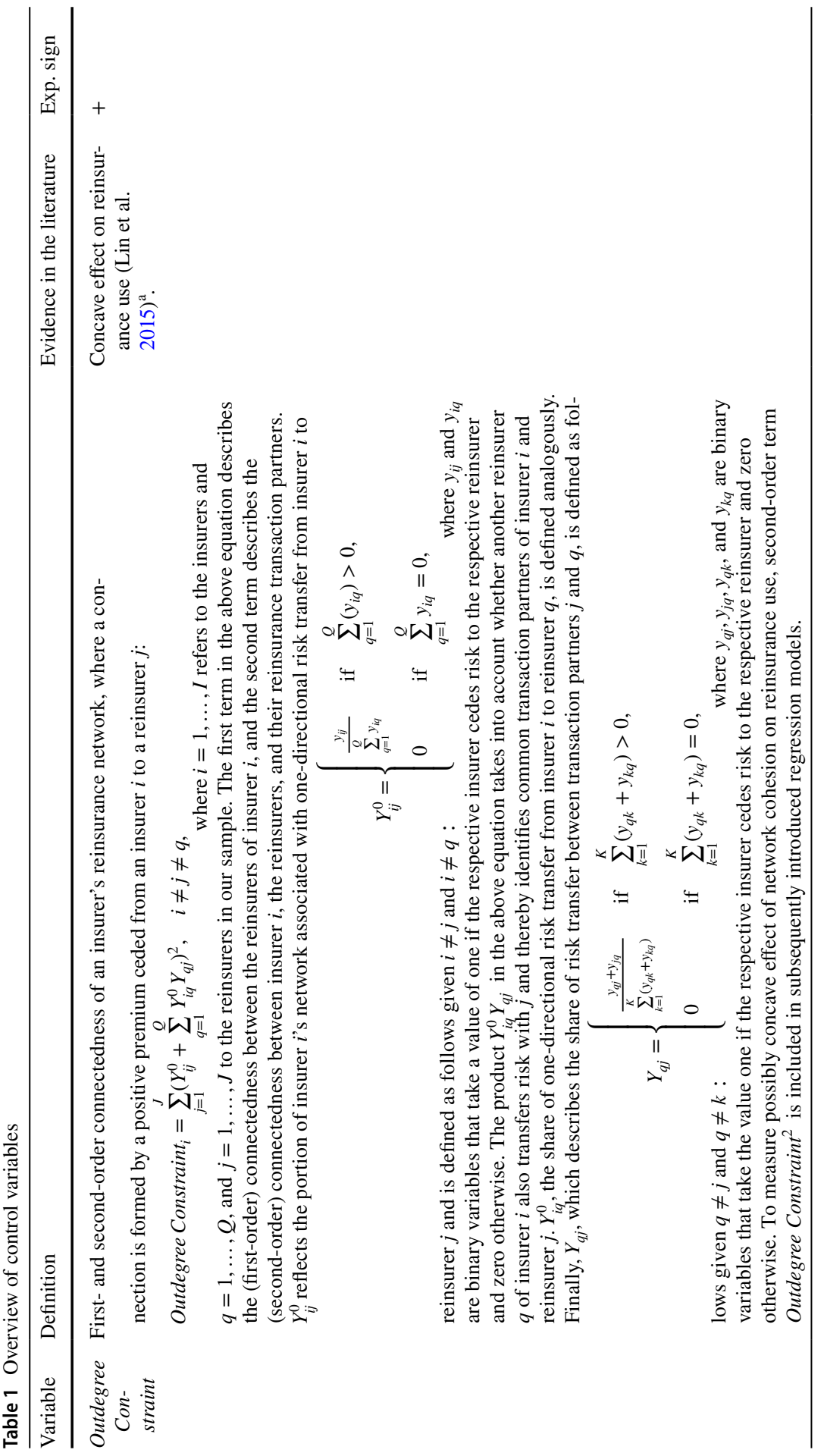

站。 


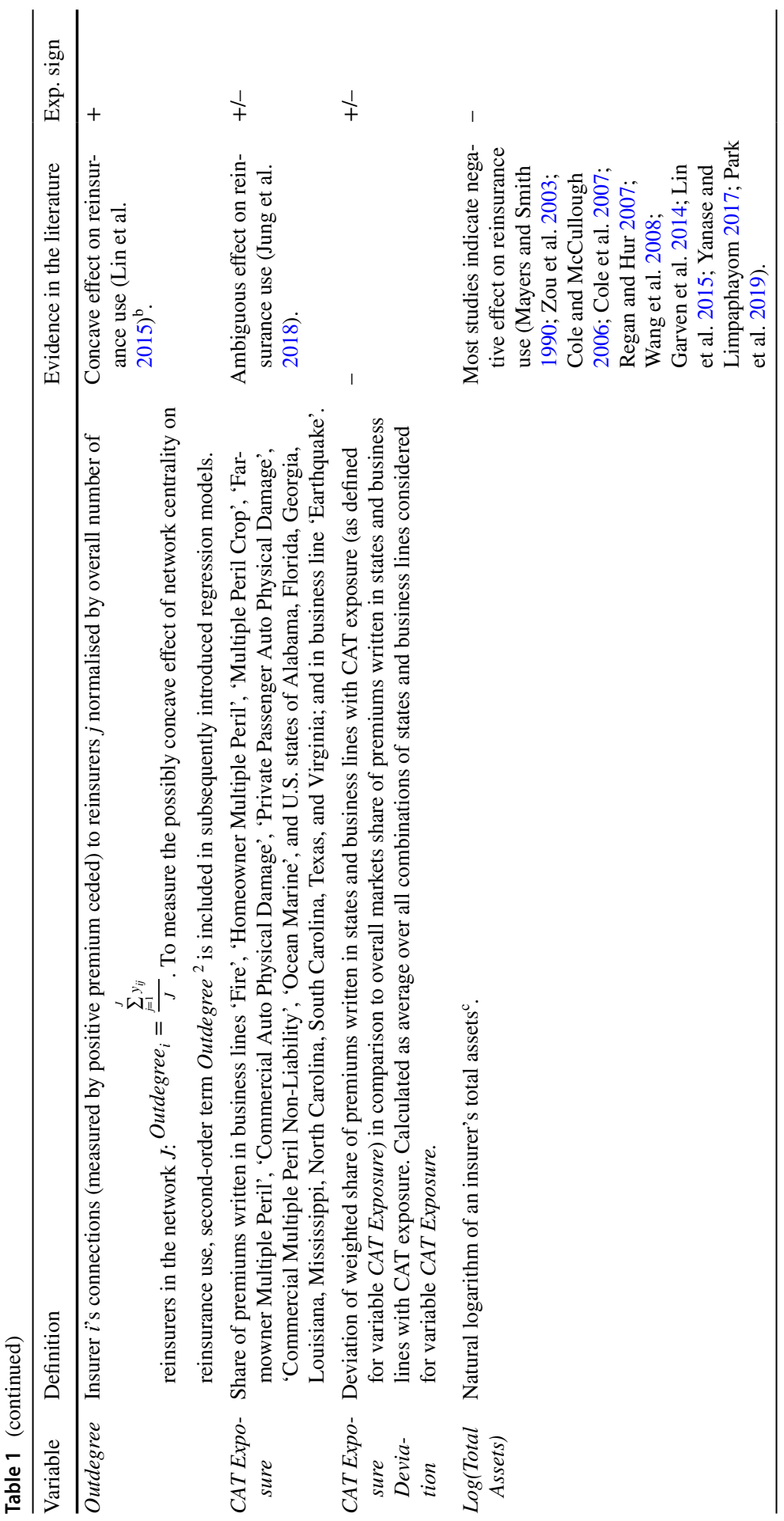




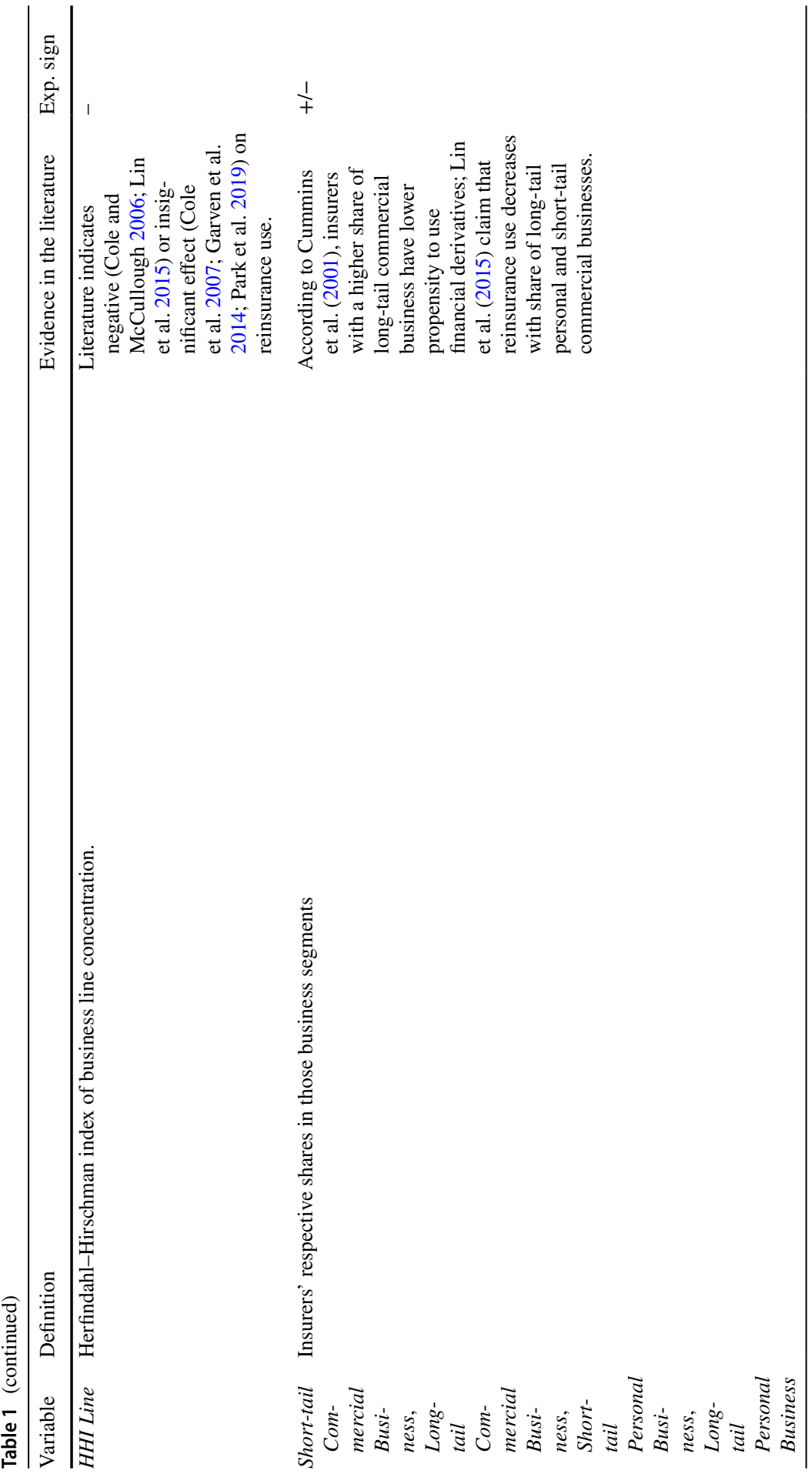

我造 


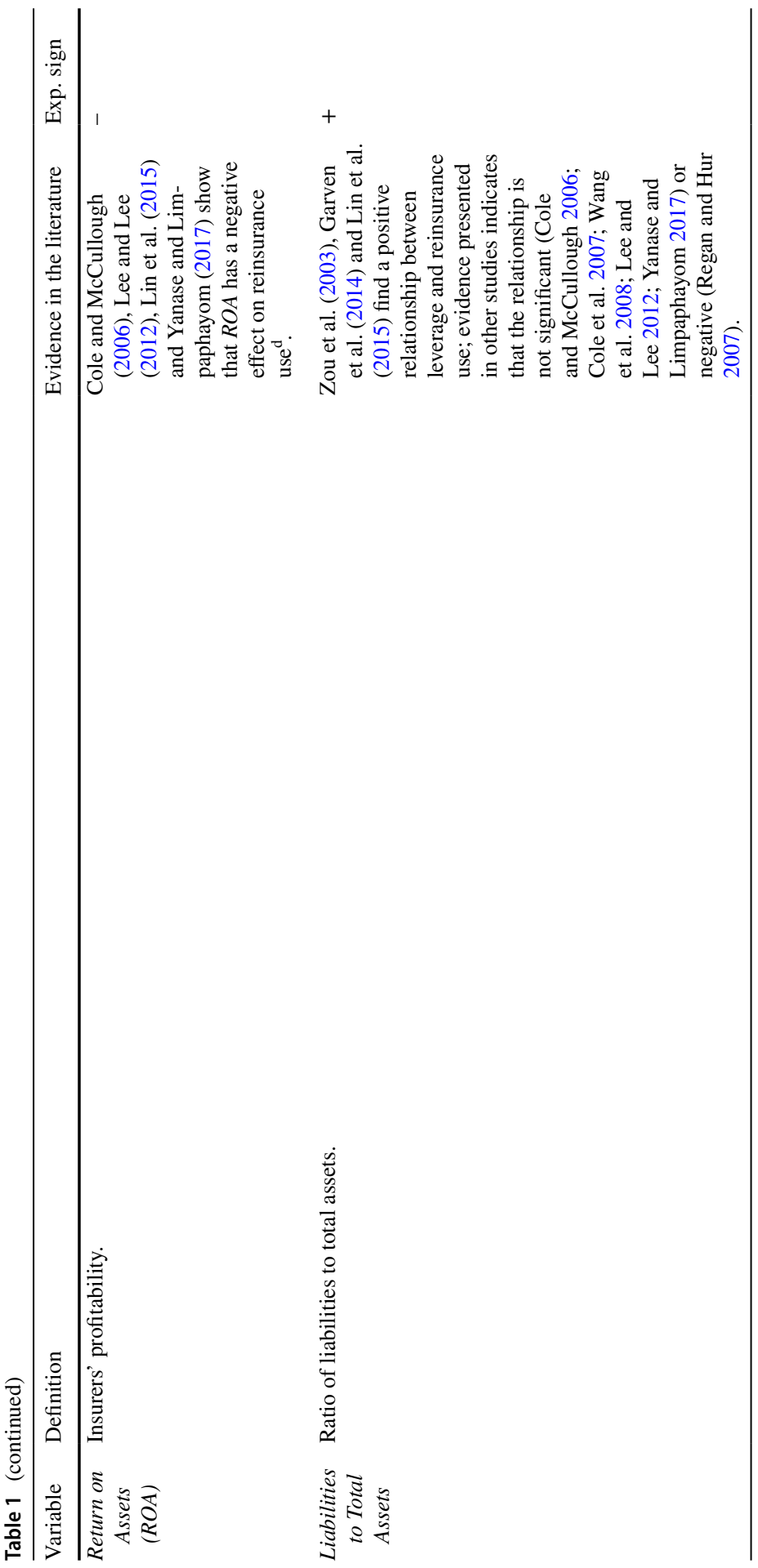




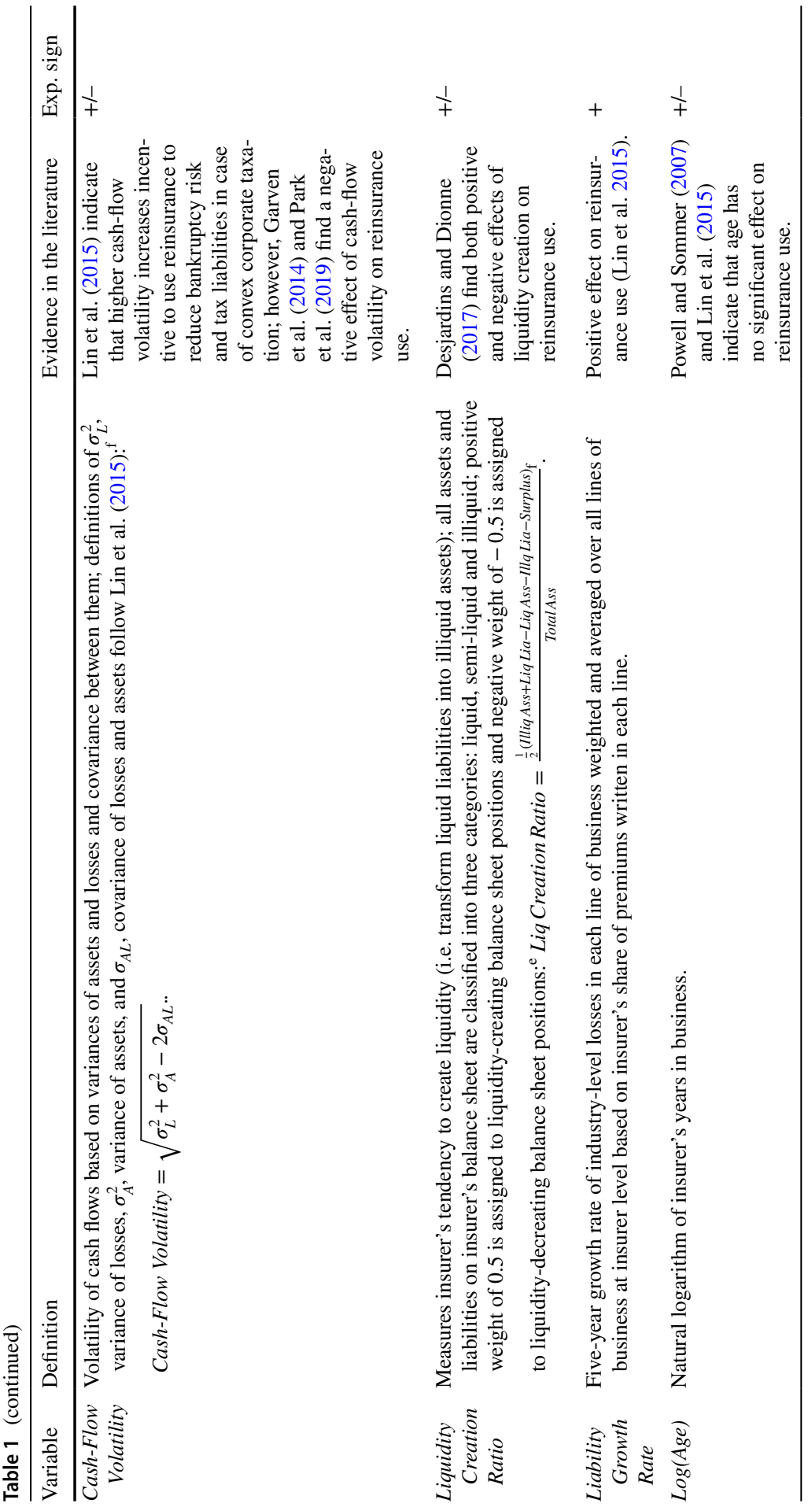

我造 


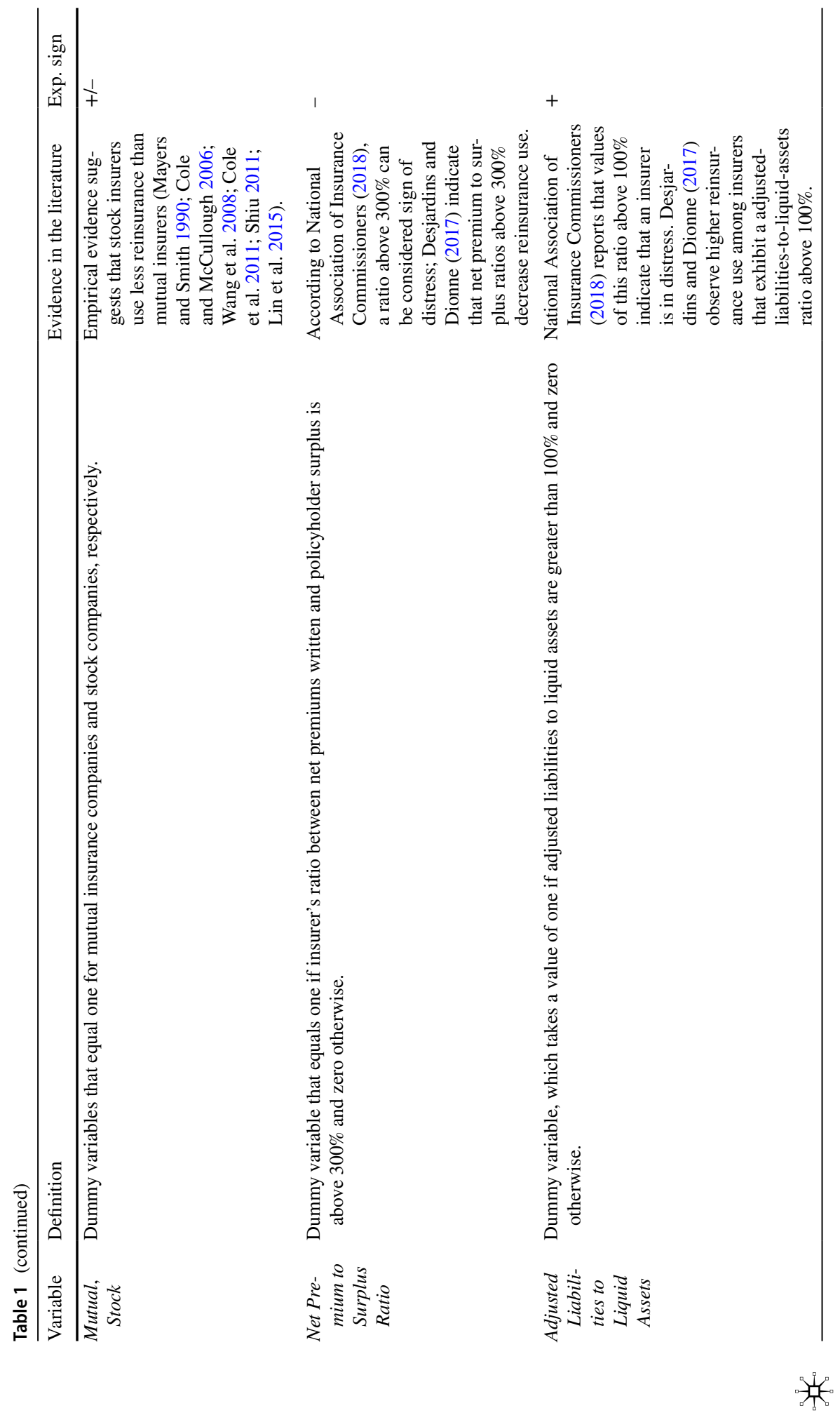




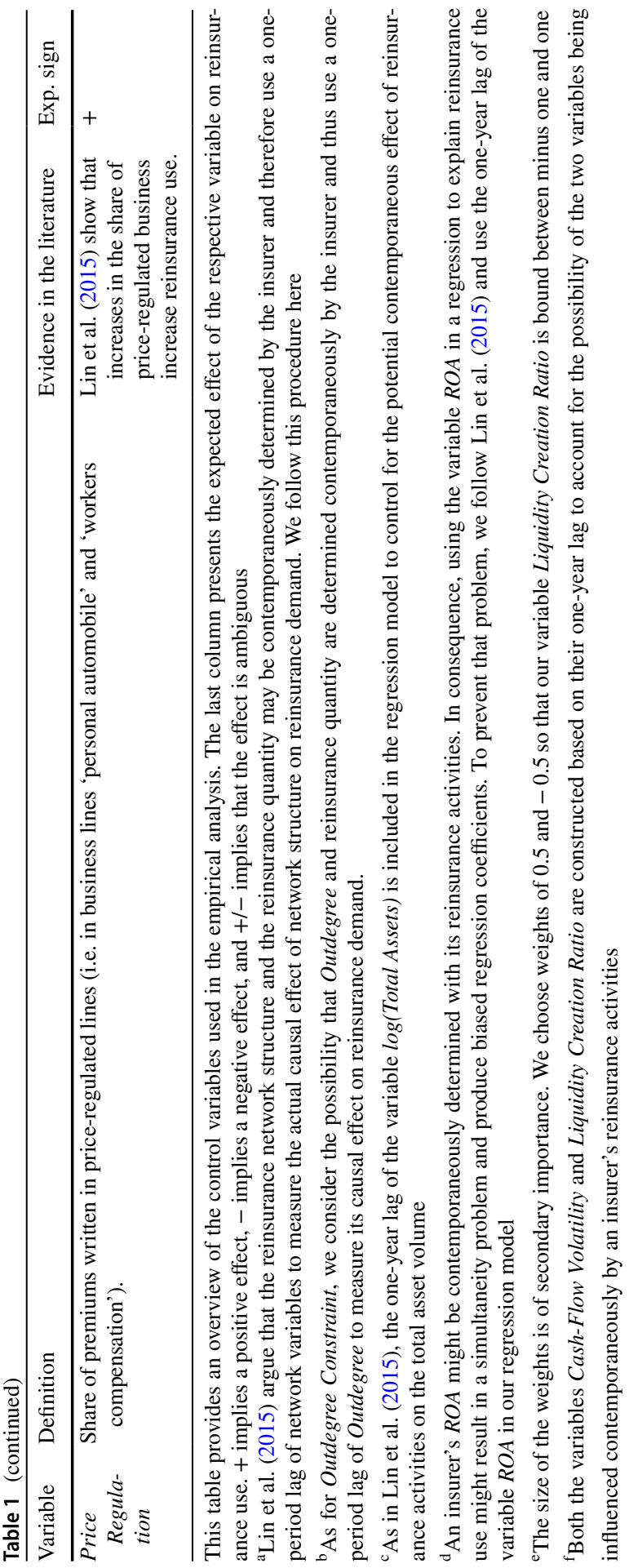

称。 
insurer in our sample has a total asset volume of USD 113.6 million. Business line concentration, measured by Business Line HHI, has a mean value of 0.566 . On average, $25.6 \%$ of the business is written in long-tail personal lines and $6.9 \%$ of the business belongs to short-tail personal lines. Short-tail commercial lines comprise on average $11.4 \%$ of an insurer's business. The remaining business is written in longtail commercial lines. The mean ROA is $2.7 \%$, and the mean Liabilities to Total Assets ratio is $55.5 \%$. The mean value of Cash-Flow Volatility is 0.141 . Liquidity Creation Ratio has a mean of - 0.515, while Liability Growth Rate has a mean of 0.035 . The mean age of an insurer in our sample is 36 years. Most of the insurers are stock companies with a share of $50.9 \%$; they are followed by mutual companies, with a share of $26.7 \%$. Of the sample insurers, $2.5 \%$ have a Net Premium to Surplus ratio above $100 \%$. The mean value of the dummy variable Adj. Liabilities to Liquid Assets indicates that $7.9 \%$ of the insurers in our sample are in regulatory distress. Moreover, $28.1 \%$ of the business of the average insurer in our sample is subject to price regulation.

Table 3 exhibits a comparison of means of the dependent and the explanatory variables between the groups of companies that do not sponsor a CAT bond over the sample period and the companies that do. The comparison shows that reinsurance use is lower among the companies that sponsor CAT bonds. The difference in comparison with the remaining companies of $6.1 \%$ is statistically significant $(p<0.1 \%)$. With respect to the explanatory variables used to test our hypotheses, we observe that CAT bond sponsoring insurers (1) have reinsurers with a better average rating, (2) are more geographically diversified, and (3) have more sustainable reinsurance relationships. For the majority of the control variables, we also observe significant differences between the two groups of companies so that it appears reasonable to include them in our empirical models.

Table 4 presents descriptive statistics on the CAT bonds in the sample. Overall, 223 CAT bond transactions are included with a mean volume of USD 141 million. The mean risk premium is $7.5 \%$ and the mean expected loss is $2.4 \%$. The bonds' maturity has a mean value of 38 months. With $68.2 \%$, the majority of bonds in the sample have an indemnity trigger, whereas $31.8 \%$ have a non-indemnity trigger.

Table 5 presents the correlations between the dependent and explanatory variables of our analysis. We observe a positive correlation between Reinsurance Ratio and CAT Bond Ratio. The positive correlation between Reinsurance Ratio and Indemnity CAT Bond Ratio is slightly more pronounced; for Non-Indemnity CAT Bond Ratio, we observe a small negative correlation with the dependent variable. Furthermore, we observe a positive relationship between Reinsurance Ratio and the variables Average Reinsurer Rating, Geographic HHI, Outdegree Constraint, CAT Exposure, CAT Exposure Deviation, HHI Line, Long-tail Personal Business, Short-tail Commercial Business, Cash-Flow Volatility, Liquidity Creation Ratio and Liability Growth Rate. By contrast, Missing Rating Information, Reinsurance Sustainability Index, Outdegree, log(Total Assets), Short-tail Personal Business, ROA, Liabilities to Total Assets, log(Age) and Price Regulation are negatively correlated with Reinsurance Ratio. In the following section, we establish a regression model to analyse the relationship between reinsurance and CAT bond use in a multivariate context. 


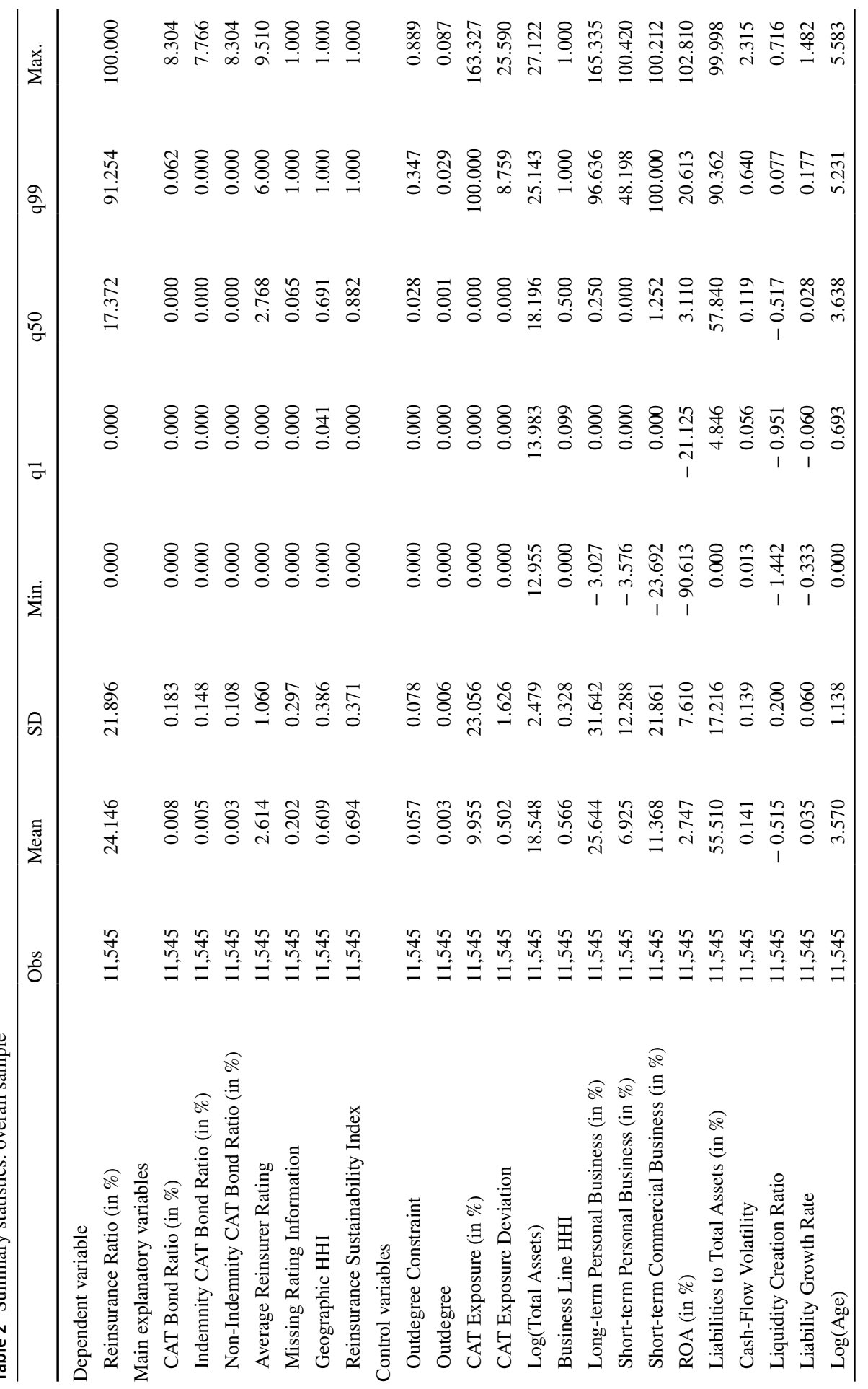

尔 


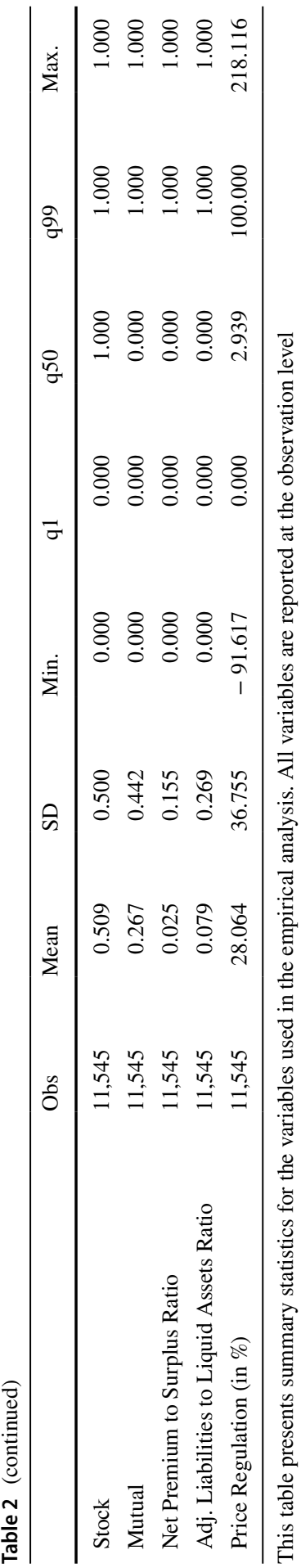


Table 3 Summary statistics: comparison of CAT bond-sponsoring and other companies

\begin{tabular}{|c|c|c|c|}
\hline & No CB sponsors & CB sponsors & Difference \\
\hline \multicolumn{4}{|l|}{ Dependent Variable } \\
\hline Reinsurance Ratio & 24.334 & 18.277 & $6.056 * * *$ \\
\hline \multicolumn{4}{|l|}{ Main Explanatory Variables } \\
\hline Average Reinsurer Rating & 2.622 & 2.355 & $0.268 * * *$ \\
\hline Missing Rating Information & 0.200 & 0.247 & $-0.047 * *$ \\
\hline Geographic HHI & 0.621 & 0.241 & $0.381 * * *$ \\
\hline Reinsurance Sustainability Index & 0.690 & 0.826 & $-0.136 * * *$ \\
\hline \multicolumn{4}{|l|}{ Control Variables } \\
\hline Outdegree Constraint & 0.058 & 0.015 & $0.0431 * * *$ \\
\hline Outdegree & 0.002 & 0.019 & $-0.016 * * *$ \\
\hline CAT Exposure & 9.441 & 26.053 & $-16.612 * * *$ \\
\hline CAT Exposure Deviation & 0.496 & 0.691 & $-0.194 *$ \\
\hline Log(Total Assets) & 18.396 & 23.296 & $-4.900 * * *$ \\
\hline Business Line HHI & 0.575 & 0.280 & $0.295 * * *$ \\
\hline Long-Term Personal Business & 25.328 & 35.554 & $-10.226 * * *$ \\
\hline Short-Term Personal Business & 6.826 & 10.023 & $-3.197 * * *$ \\
\hline Short-Term Commercial business & 11.154 & 18.070 & $-6.916^{* * *}$ \\
\hline ROA & 2.687 & 4.618 & $-1.930 * * *$ \\
\hline Liabilities to Total Assets & 55.317 & 61.548 & $-6.231 * * *$ \\
\hline Cash-flow Volatility & 0.142 & 0.106 & $0.037 * * *$ \\
\hline Liquidity Creation Ratio & -0.518 & -0.436 & $-0.0823 * * *$ \\
\hline Liability Growth Rate; & 0.035 & 0.044 & $-0.000 * *$ \\
\hline $\log ($ Age $)$ & 3.548 & 4.260 & $-0.712 * * *$ \\
\hline Stock & 0.499 & 0.812 & $-0.313 * * *$ \\
\hline Mutual & 0.274 & 0.036 & $0.238 * * *$ \\
\hline Net Premium to Surplus Ratio & 0.025 & 0.006 & $0.019 *$ \\
\hline Adj. Liabilities to Liquid Assets ratio & 0.079 & 0.059 & 0.020 \\
\hline Price Regulation & 27.979 & 30.750 & -2.771 \\
\hline
\end{tabular}

This table presents a comparison of means between the companies that sponsor a CAT bond at least once over the sample period and the remaining companies. The first column presents the means of companies that do not sponsor a CAT bond over the sample period and the second column presents the means of companies that sponsor a CAT bond at least once over the sample period. The third column presents the difference in means. The symbols ${ }^{\dagger}, *, * *$ and $* * *$ indicate statistical significance at the $10 \%, 5 \%, 1 \%$ and $0.1 \%$ levels, respectively

\section{Empirical results}

In the empirical analysis, we first establish our baseline model and regress the dependent variable Reinsurance Ratio on the explanatory variables introduced in 'Variables' section based on our overall sample and the subsample of CAT bond-sponsoring insurers. We initially do not distinguish CAT bonds with respect to their EL or trigger type. Second, we separately consider CAT bonds with 
indemnity triggers and CAT bonds with non-indemnity triggers in our baseline regression model. Third, we test the hypotheses developed in 'Background, literature review, and hypotheses' section. To test the reinsurer default risk hypothesis (H1), we divide our data set into subsamples by grouping insurers based on their exposure to reinsurer default risk, measured through the Average Reinsurer Rating. The risk layer hypothesis (H2) examines the effect of CAT bond use on reinsurance use depending on the CAT bonds' risk layer. Therefore, we incorporate Indemnity CAT Bond Ratio ${ }^{\left[E L_{\gamma_{1}}, \underline{E L}_{\gamma_{2}}\right)}$, and Non-Indemnity CAT Bond Ratio ${ }^{\left[E L_{\gamma_{1}}, \underline{E L}_{\gamma_{2}}\right)}$ in our model. To test the basis risk hypothesis (H3), we subsample the insurers in the sample based on their Geographic HHI, and to test the asymmetric information hypothesis (H4), we subsample insurers based on their Reinsurance Sustainability Index. Fourth, we alternatively test the hypotheses $(\mathrm{H} 2)$ to $(\mathrm{H} 4)$ by introducing interaction terms between the CAT bond-specific variables and the variables used to test the respective hypotheses. Finally, we rerun our analyses using a dynamic model estimated with the generalised method of moments (GMM). ${ }^{12}$

\section{Baseline model}

Our regression models are all estimated using fixed effects estimation. We withintransform the dependent and explanatory variables to partial unobservable insurerfixed effects out of our data. The strength of fixed effects estimation is that it provides consistent estimators, even if the explanatory variables are correlated with the unobservable insurer-specific effect (Baltagi 2013; Wooldridge 2015). The model has the following structure:

$$
\text { ReinsuranceRatio }_{i t}=\gamma^{\prime} \ddot{Y}_{t}+\delta^{\prime} \ddot{Z}_{i t}+\ddot{u}_{i t},
$$

for insurers $i=1, \ldots, n$ and points in time $t=1, \ldots, T$. $Y_{t}$ contains variables that vary only over time (in our models year fixed effects). $Z_{i t}$ are variables that vary by insurer bond (sponsor) and time, similar to CAT Bond Ratio. Since the variables in this model are within-transformed, the double dot notation indicates that the variables are expressed as deviations from their means.

Table 6 presents the results for our baseline regression model. In model (I.1) we regress Reinsurance Ratio on the main explanatory and control variables introduced in 'Variables' section. To model the effect of CAT bonds, we initially include only CAT Bond Ratio. Model (I.2) includes the same explanatory variables as are used in model (I.1), but the regression in this model is based only on companies that sponsored a CAT bond at least once over the observed sample period. In models (I.3) and (I.4), we distinguish between CAT bonds withwindemnity

\footnotetext{
12 Apart from the already mentioned robustness checks, we conduct a series of further robustness checks to examine the validity of our results in modified settings. In Section D of the Online Appendix, we test how the occurrence of natural catastrophes influences our results. In Section E, we examine the influence of outliers in the CAT bond-specific variables. In Section G, we replace the year fixed effects with the the variable Rate-on-Line, a measure for the price level in the reinsurance market.
} 


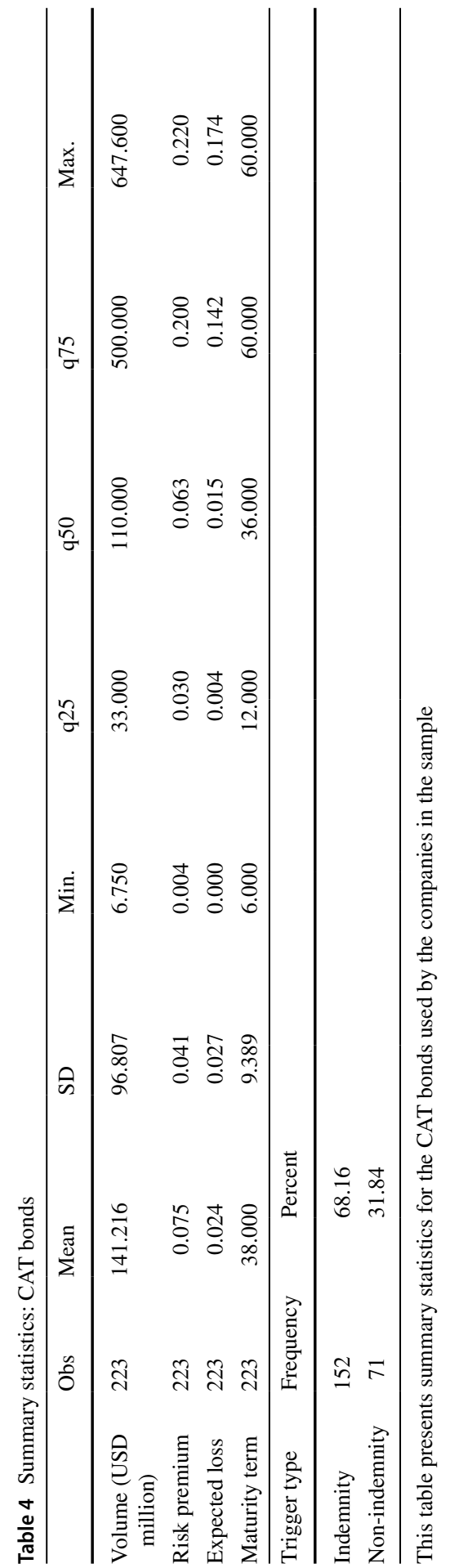




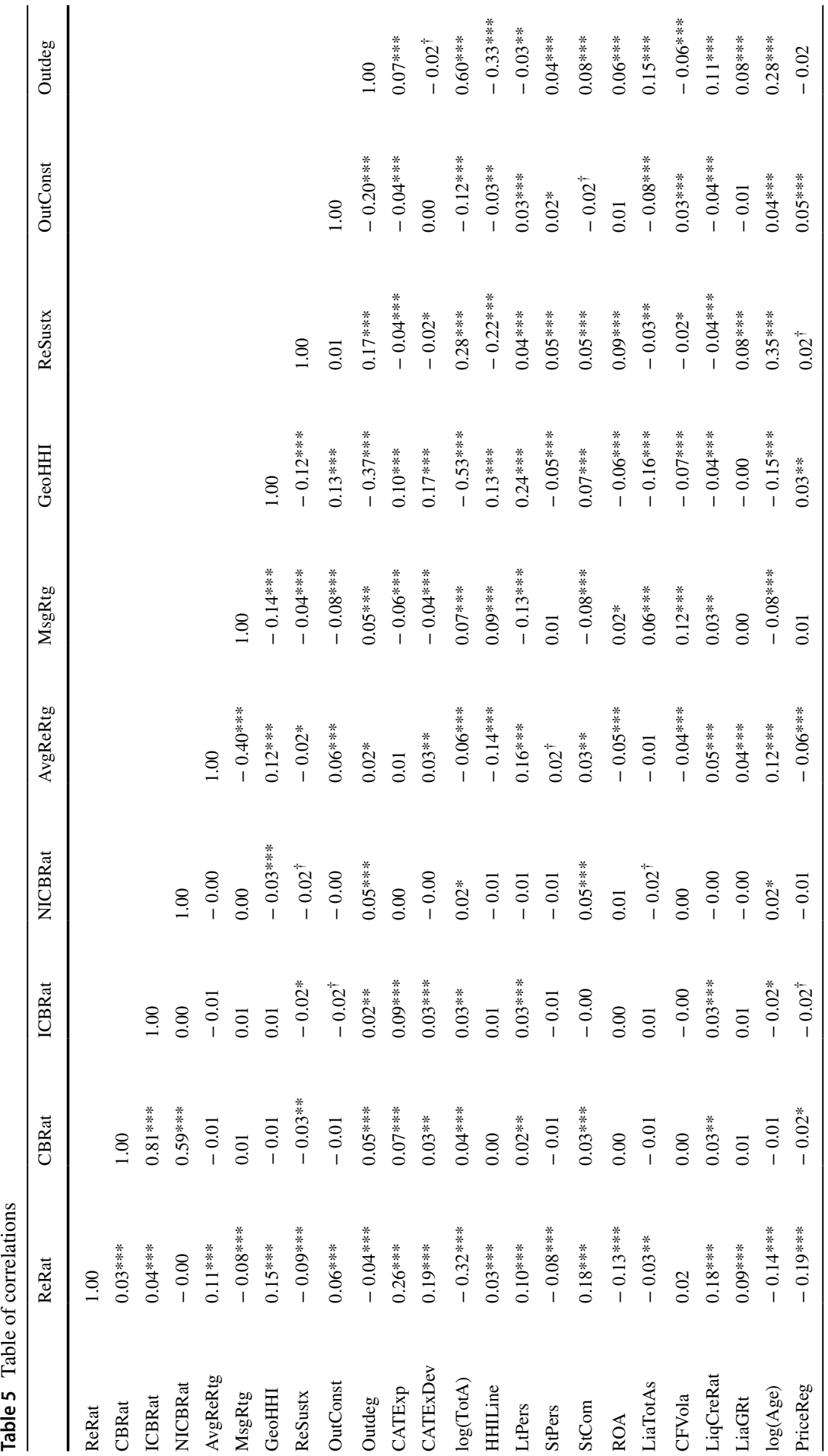




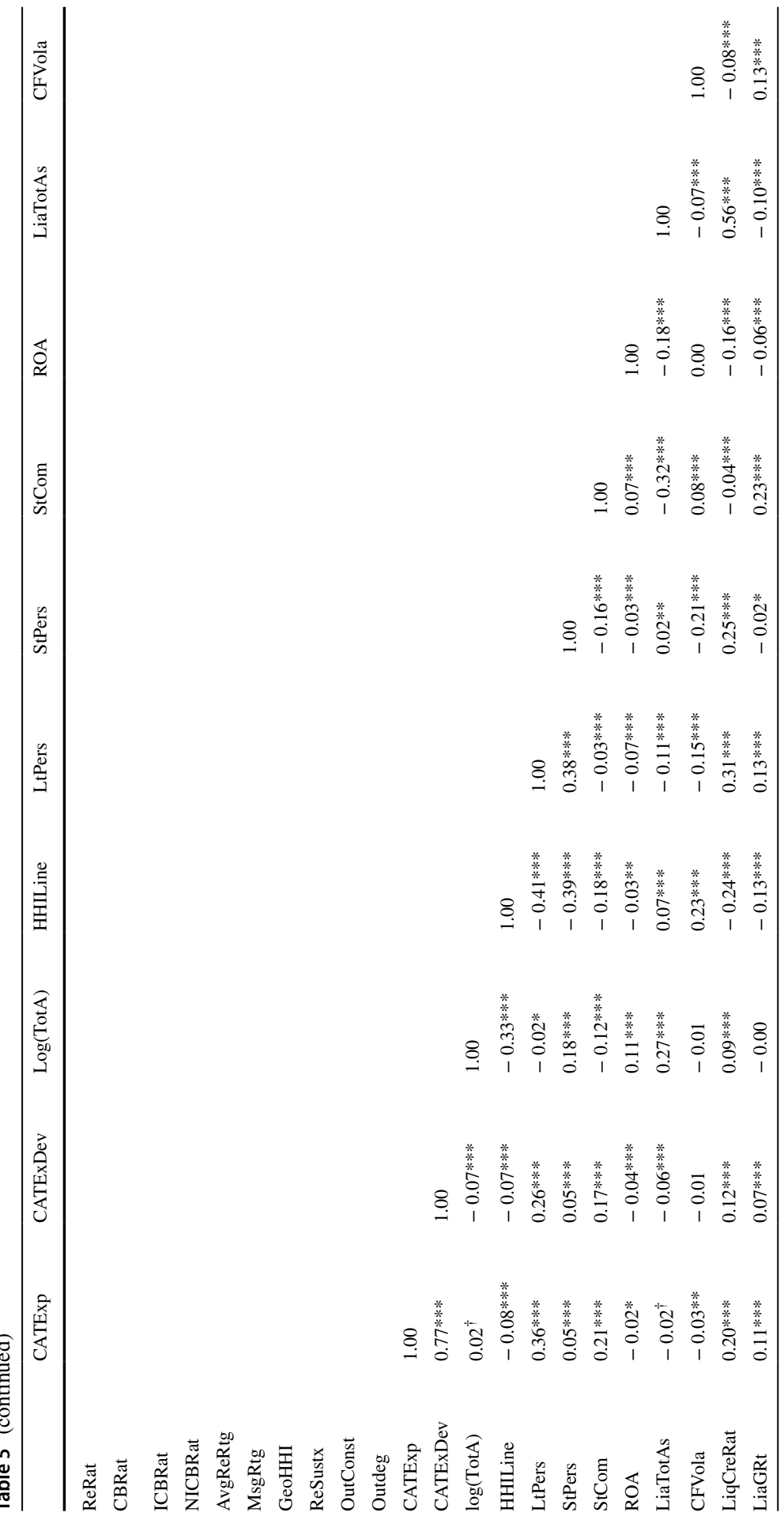

起。 


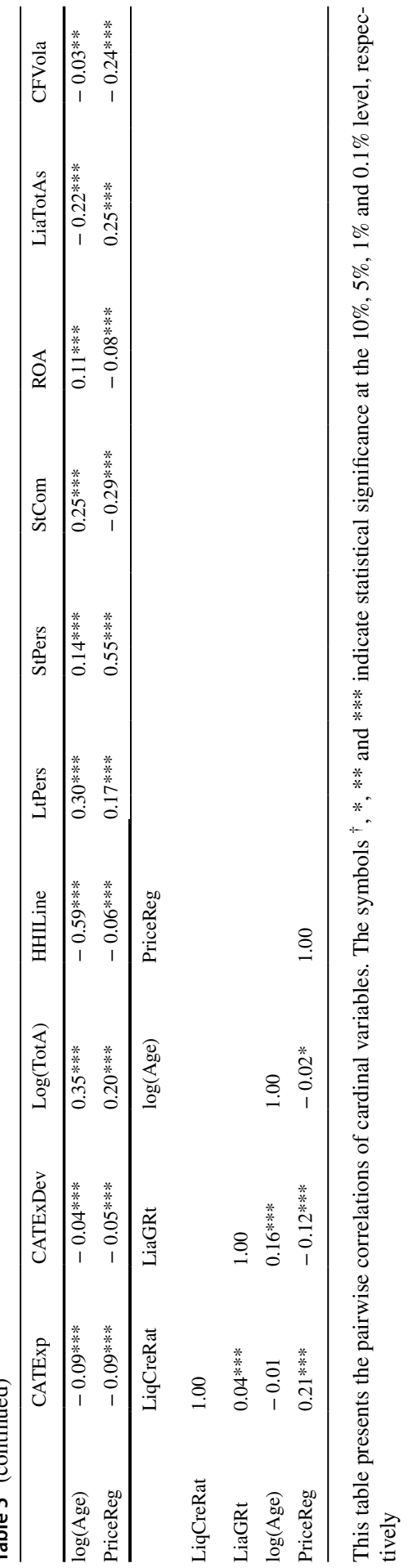


Table 6 Baseline model: influence of CAT bonds on reinsurance use

Full sample CAT bond sample Full sample CAT bond sample (I.1) (I.2)

(I.3)

(I.4)

\begin{tabular}{lll}
\hline L.CAT Bond Ratio & -0.44 & 0.09 \\
& $(0.74)$ & $(0.94)$
\end{tabular}

L.Indemnity CAT Bond Ratio

0.53

1.49

(0.60)

(1.32)

L.Non-Indemnity CAT Bond Ratio

$-1.86 * * * \quad-1.92 * *$

(0.27)

(0.56)

Average Reinsurer Rating

$0.42^{\dagger}$

$3.45 *$

$0.42^{\dagger}$

$3.24^{\dagger}$

Missing Rating Information

(0.25)

(1.69)

(0.25)

(1.64)

$-0.52 \quad 3.25$

$-0.52$

3.03

(1.01)

(3.50)

(1.01)

(3.55)

Geographic HHI

$-1.93$

6.14

$-1.94$

7.20

(2.38) (12.54)

(2.38)

(12.58)

Reinsurance Sustainability Index

$-1.25 * * \quad-6.55$

$-1.27 * * \quad-10.68 * *$

(0.47) (4.56)

(0.47)

(3.60)

L.Outdegree Constraint

5.30

$-88.69$

5.31

$-71.51$

L.Outdegree Constraint ${ }^{2}$

(4.26)

(134.32)

(4.26)

(134.90)

$-6.49 \quad 562.09$

$-6.51$

435.26

(9.80) (780.87)

(9.80)

(787.30)

L.Outdegree

$449.11^{* * *} \quad 273.04^{\dagger}$

$448.15^{* * *} \quad 281.33^{\dagger}$

L.Outdegree ${ }^{2}$

(123.92) (155.90)

(124.19) (157.85)

- $3836.60-1991.35$

$-3835.01-2213.00$

(2593.27) (2604.81)

(2621.00) (2713.70)

CAT Exposure

0.12

0.16

0.12

0.06

(0.09)

(0.40)

(0.09)

(0.37)

CAT Exposure Deviation

$-0.32$

$-6.66$

$-0.31$

$-4.82$

(0.73)

(4.91)

(0.73)

(4.83)

$\log$ (Total Assets)

$-4.72 * * *-3.06$

$-4.71 * * * \quad-2.22$

(0.80)

(2.62)

Geographic HHI

$-1.93$

6.14

(0.80)

(2.45)

(2.38)

(12.54)

$-1.94$

7.20

(2.38)

(12.58)

Business Line HHI

$-3.49$

$-50.85^{*}$

$-3.46$

$-45.54 *$

(3.37)

(20.96)

(3.37)

(20.75)

Long-term Personal Business

0.03

$-0.07$

0.03

$-0.06$

(0.06)

(0.15)

(0.06)

(0.14)

Short-term Personal Business

$-0.15$

$-0.54^{\dagger}$

$-0.15$

$-0.49$

(0.15)

(0.31)

(0.15)

(0.30)

Short-term Commercial Business

$0.13 *$

$-0.38 * *$

$0.13 *$

$-0.32 *$

(0.06)

(0.12)

(0.06)

(0.13)

L.ROA

$-0.00$

0.11

$-0.00$

0.10

(0.02)

(0.19)

(0.02)

(0.18)

Liabilities to Total Assets

$0.08 * * \quad-0.38$

$0.08 * *$

$-0.36$ 
Table 6 (continued)

\begin{tabular}{|c|c|c|c|c|}
\hline & $\begin{array}{l}\text { Full sample } \\
\text { (I.1) }\end{array}$ & $\begin{array}{l}\text { CAT bond sample } \\
\text { (I.2) }\end{array}$ & $\begin{array}{l}\text { Full sample } \\
\text { (I.3) }\end{array}$ & $\begin{array}{l}\text { CAT bond sample } \\
\text { (I.4) }\end{array}$ \\
\hline & $(0.03)$ & $(0.23)$ & $(0.03)$ & $(0.24)$ \\
\hline \multirow[t]{2}{*}{ L.Cash-Flow Volatility } & 2.06 & $-26.26^{\dagger}$ & 2.12 & -22.96 \\
\hline & $(5.71)$ & $(14.55)$ & $(5.71)$ & $(14.04)$ \\
\hline \multirow[t]{2}{*}{ L.Liquidity Creation Ratio } & $11.35 * * *$ & $36.34 * *$ & $11.34 * * *$ & $35.43^{*}$ \\
\hline & $(2.32)$ & $(13.29)$ & $(2.32)$ & $(13.63)$ \\
\hline \multirow[t]{2}{*}{ Liability Growth Rate } & $3.63^{\dagger}$ & $80.14 *$ & $3.61^{\dagger}$ & $73.64 *$ \\
\hline & $(1.95)$ & $(31.36)$ & $(1.95)$ & $(31.74)$ \\
\hline \multirow[t]{2}{*}{ Log(Age) } & 0.39 & -6.02 & 0.38 & -6.44 \\
\hline & $(0.91)$ & $(4.23)$ & $(0.91)$ & $(4.10)$ \\
\hline \multirow[t]{2}{*}{ Stock } & 0.44 & -0.02 & 0.45 & 0.02 \\
\hline & $(0.33)$ & $(0.56)$ & $(0.33)$ & $(0.53)$ \\
\hline \multirow[t]{2}{*}{ Mutual } & 0.28 & $-2.26^{*}$ & 0.28 & $-2.17^{*}$ \\
\hline & $(0.48)$ & $(0.96)$ & $(0.48)$ & $(0.99)$ \\
\hline \multirow[t]{2}{*}{ Net Premium to Surplus Ratio } & $-6.17 * * *$ & 6.12 & $-6.17 * * *$ & 3.91 \\
\hline & $(1.21)$ & $(5.78)$ & $(1.21)$ & $(5.15)$ \\
\hline \multirow{2}{*}{$\begin{array}{l}\text { Adj. Liabilities to Liquid Assets } \\
\text { Ratio }\end{array}$} & $2.89 * *$ & $5.73 * *$ & $2.87 * *$ & $5.30 * *$ \\
\hline & $(0.92)$ & $(1.63)$ & $(0.92)$ & $(1.50)$ \\
\hline \multirow[t]{2}{*}{ Price Regulation } & 0.00 & -0.14 & 0.00 & -0.13 \\
\hline & $(0.05)$ & $(0.12)$ & $(0.05)$ & $(0.12)$ \\
\hline \multirow[t]{2}{*}{ Constant } & $109.62 * * *$ & $178.51^{*}$ & $109.59 * * *$ & $160.32 *$ \\
\hline & $(15.04)$ & $(72.61)$ & $(15.04)$ & (71.01) \\
\hline Year fixed effects & Yes & Yes & Yes & Yes \\
\hline Observations & 11,545 & 357 & 11,545 & 357 \\
\hline Within- $R^{2}$ & 0.055 & 0.447 & 0.055 & 0.465 \\
\hline Adjusted within- $R^{2}$ & 0.052 & 0.379 & 0.052 & 0.397 \\
\hline
\end{tabular}

This table reports fixed effects estimates of company- and CAT bond-specific variables on the Reinsurance Ratio. Columns (I.1) and (I.3) present the results for the full sample, whereas in columns (I.2) and (I.4) the sample is limited to companies that sponsor a CAT bond at least once over the sample period. In columns (I.3) and (I.4), CAT bonds are distinguished in terms of their trigger type by Indemnity CAT Bond Ratio and Non-Indemnity CAT Bond Ratio. Standard errors, which are shown in parentheses, are clustered at the company level and robust to heteroscedasticity. The symbols ${ }^{\dagger}, *, * *$ and $* * *$ indicate statistical significance at the $10 \%, 5 \%, 1 \%$ and $0.1 \%$ levels, respectively

triggers and CAT bonds with non-indemnity triggers for the overall sample and the subsample of CAT bond-sponsoring companies, respectively.

The variable CAT Bond Ratio is not significant in either model (I.1) or (I.2), which implies that there is no general substitution effect between reinsurance and CAT bonds. However, when we distinguish CAT bonds by their trigger type in models (I.3) and (I.4), we find a highly significantly negative effect $(p<0.1 \%)$ of nonindemnity CAT bonds on Reinsurance Ratio, which indicates that non-indemnity CAT bonds substitute for reinsurance. By contrast, for indemnity CAT bonds, we 
observe an insignificant effect on reinsurance use. Based on the reasoning of the theoretical literature, this result may be a first indication that indemnity CAT bonds serve as a complement for reinsurance, whereas the added value to insurers' risk management strategies stems from non-indemnity CAT bonds (Nell and Richter 2004). In the next section, we examine this assumption and first test the influence of insurers' exposure to reinsurer default risk.

\section{Effect of reinsurer default risk}

This section analyses the effect of insurers' exposure to reinsurer default risk on the use of reinsurance and CAT bonds. We use the average rating of an insurer's reinsurance counterparties as a proxy for default risk (Park et al. 2019). The results of this analysis are shown in Panel A of Table 7. We divide our sample into two parts based on the magnitude of the reinsurer default risk measured by Average Reinsurer Rating. The sample is split into two parts at the cross-sectional level based on the median over-time average Average Reinsurer Rating among the CAT bond-sponsoring insurers. Insurers that exhibit a below-median average Average Reinsurer Rating level face low reinsurer default risk, whereas reinsurer default risk is high for insurers with an above-median average level. The company-specific control variables are the same as those used in models (I.1) to (I.4) but are omitted to conserve space. ${ }^{13}$ The regression results for insurers with low reinsurer default risk are presented in column (II.1) for the full sample and in column (II.2) for the subsample of CAT bond sponsors. Columns (II.3) and (II.4) present the results for insurers with high reinsurer default risk for the full sample and the subsample of CAT bond sponsors, respectively. We do not distinguish between the CAT bonds' trigger type, because CAT bonds reduce reinsurer default risk irrespective of the trigger type.

Our results do not exhibit substitution effects in the subsample of insurers with low reinsurer default risk (columns (II.1) and (II.2)), where the CAT Bond Ratio has an insignificant coefficient. By contrast, in the subsample of insurers with high reinsurer default risk that considers all insurers, we measure a significant negative effect of CAT bond use on reinsurance use of -1.97 ( $p<0.1 \%)$. However, in the subsample of CAT bond sponsoring insurers that effect is not significant. Consequently, the full sample results support the reinsurer default risk hypothesis (H1) and the expectations of the theoretical literature that CAT bonds add value by reducing the exposure to reinsurer default risk (Doherty and Richter 2002; Nell and Richter 2004; Cummins and Trainar 2009; Lakdawalla and Zanjani 2012; Trottier and Lai 2017; Subramanian and Wang 2018).

\footnotetext{
13 The same applies to the company-specific control variables included in the regression models introduced below.
} 


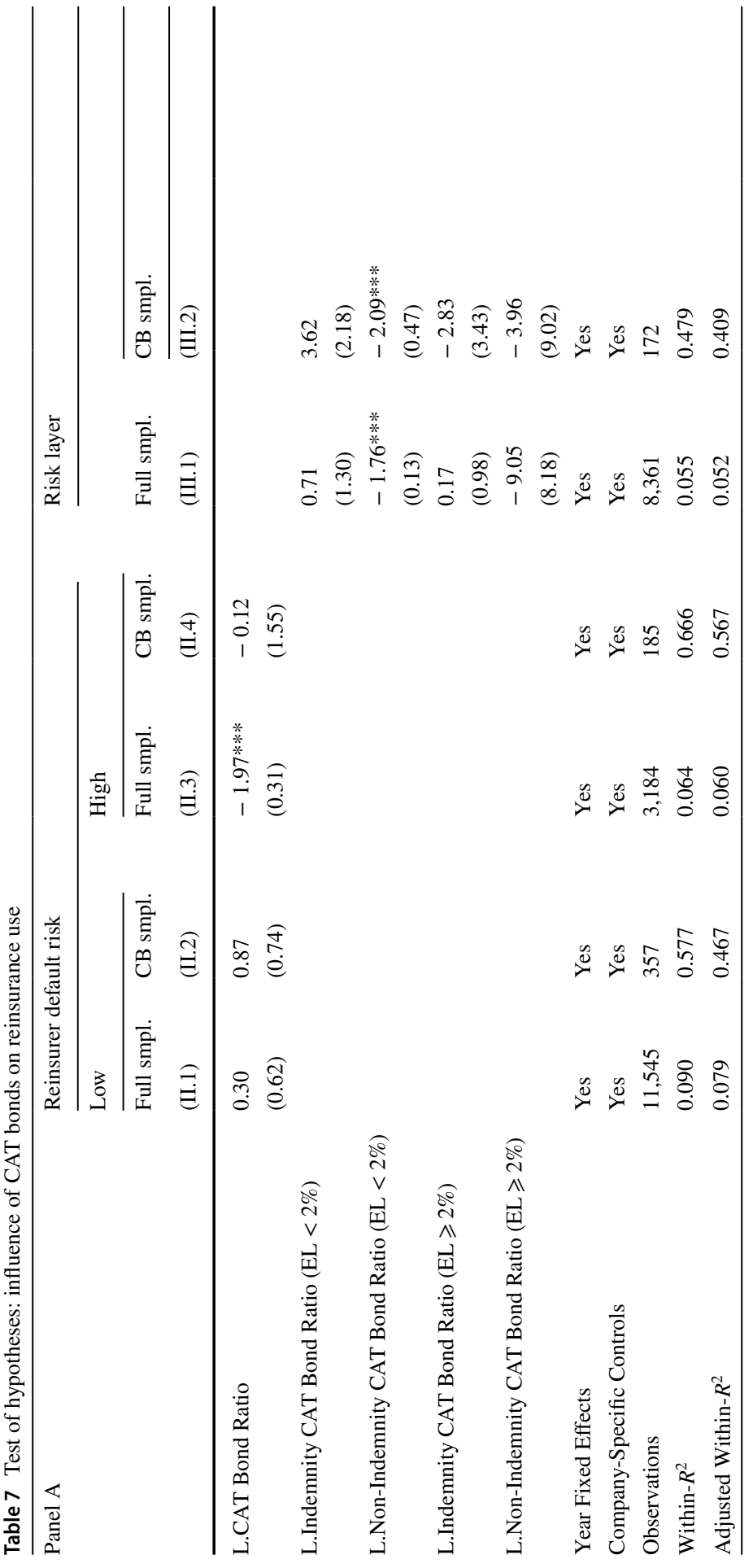




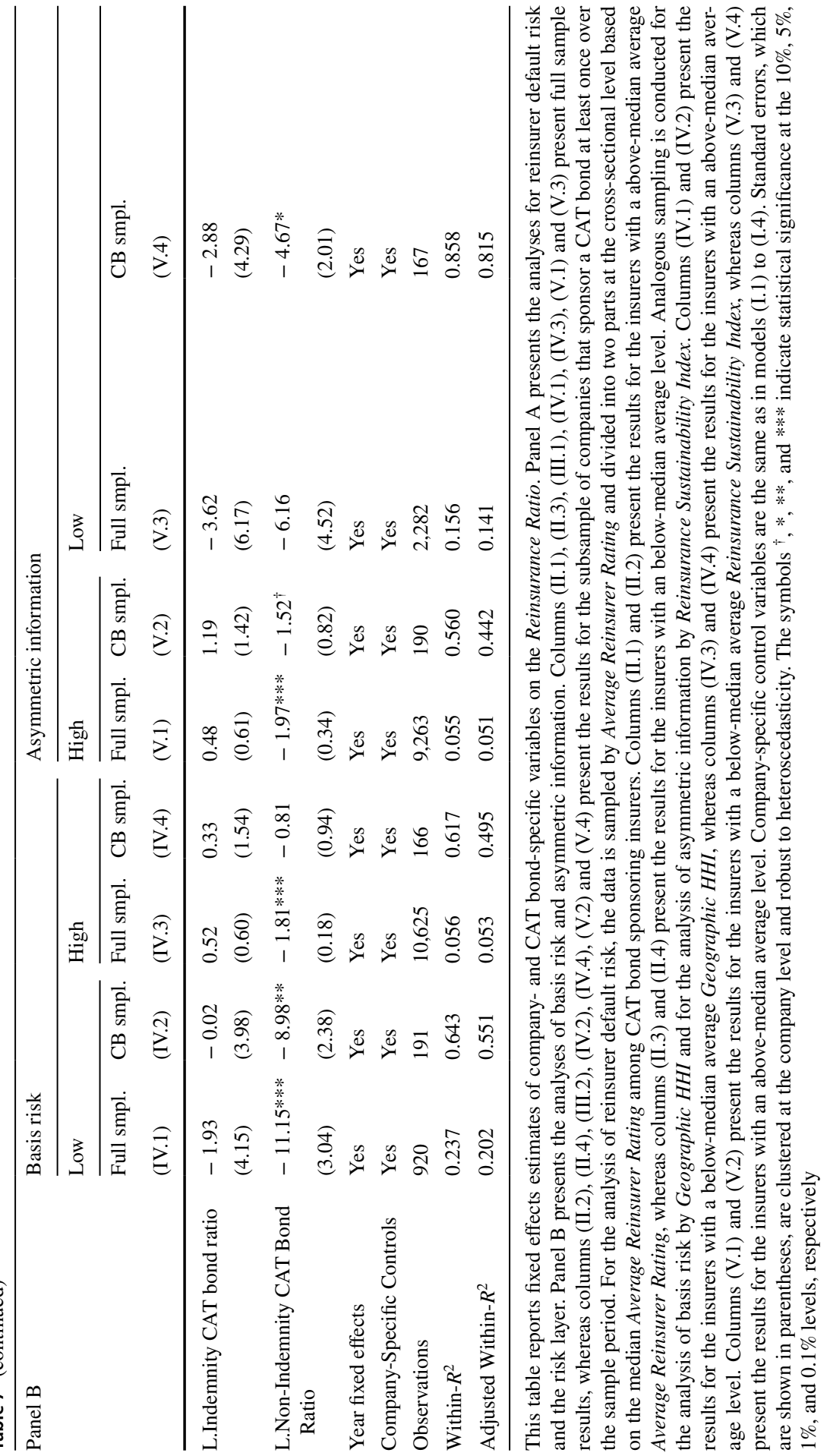




\section{Effect of risk layer}

Given the theoretical evidence that the advantageousness of CAT bonds over reinsurance depends on the insured risk layer, we conclude that reinsurance may be substituted by CAT bonds in high-risk layers. To test this assumption, we slightly mod\left. ify our baseline model and include the variables Indemnity CAT Bond Ratio ${\underline{\left[E \nu_{1}\right.}}_{1}, \underline{E L_{\gamma_{2}}}\right)$ and Non - Indemnity CAT Bond Ratio $\left.{ }^{\left[E L_{\gamma_{1}}\right.} \underline{E L}_{\gamma_{2}}\right)$ based on the EL ranges $[0 \%, 2 \%)$ and $[2 \%, 100 \%)$ introduced in the 'Variables' section to approximate high- and low-risk layers. In this analysis, we distinguish between the trigger types as they may have a relevant influence on the CAT bonds' attractiveness in different risk layers. For example, non-indemnity bonds may be more attractive in higher risk layers, where basis risk is less relevant. The results are shown in Panel A of Table 7. Column (III.1) presents the results for the full sample, and column (III.2) reports the results for the subsample of CAT bond sponsoring companies.

The results support both the theoretical evidence and our risk layer hypothesis (H2). Model (III.1) suggests that, in the high-risk layer, Non-Indemnity CAT Bond Ratio has a highly significantly negative effect on reinsurance use and that a one percentage point increase in CAT bond use decreases reinsurance use by 1.76 percentage points $(p<0.1 \%)$. In the CAT bond subsample of model (III.2), the effect is even more pronounced with 2.09 percentage points $(p<0.1 \%)$. For indemnity bonds issued in high-risk layers, we observe an insignificant effect on reinsurance use. Consequently, non-indemnity CAT bonds issued in high-risk layers add value to insurers' risk management strategies and are thus used as a substitute for reinsurance. The insignificant effect observed for indemnity CAT bonds protecting highrisk layers indicates that these serve as a complement to reinsurance. Insurers that place indemnity CAT bonds in high-risk layers may additionally purchase extensive reinsurance coverage in lower risk layers, which would confirm the results of Nell and Richter (2004). In low-risk layers, CAT bond use does not have a significant effect on reinsurance use. Overall, the analyses in models (III.1) and (III.2) support the risk layer hypothesis (H2) and indicate that the added value stems from nonindemnity CAT bonds, thus confirming the expectations of the theoretical literature (Nell and Richter 2004; Cummins and Trainar 2009; Lakdawalla and Zanjani 2012; Trottier and Lai 2017; Subramanian and Wang 2018).

\section{Effect of basis risk}

In the following, we examine the effect of basis risk on the use of reinsurance and CAT bonds. We test whether insurers replace reinsurance with non-indemnity CAT bonds if their basis risk is sufficiently low, as is assumed in the basis risk hypothesis (H3). Panel B of Table 7 presents the results of this test. We divide our sample into two parts based on insurers' exposure to basis risk, which we measure using the Geographic HHI. The sample is split into two parts at the cross-sectional level based on the median over-time average Geographic HHI among the CAT bond-sponsoring insurers. Insurers that exhibit a below-median average level of Geographic HHI have a low exposure to basis risk, whereas insurers with an above-median average 
level have a high exposure. The regression results for insurers with low basis risk are presented in column (IV.1) for the full sample and in column (IV.2) for the subsample of CAT bond sponsors. Columns (IV.3) and (IV.4) present the results for insurers with high basis risk for the full sample and the subsample of CAT bond sponsors, respectively.

After the samples are divided with respect to the insurers' basis risk, Indemnity CAT Bond Ratio is insignificant in the low basis risk subsamples and in the CAT bond sponsor subsample with high basis risk. For non-indemnity CAT bonds, we observe significant differences between insurers with high and low basis risk. In the low basis risk subsample, an increase in the use of non-indemnity bonds by one percentage point decreases reinsurance use by $11.15(p<1 \%)$ percentage points in the full sample and by a similar magnitude in the subsample of CAT bond sponsors. The magnitude of this substitution effect is significantly lower for insurers with high basis risk, amounting to $1.81(p<0.1 \%)$ percentage points in the full sample and the effect is insignificant in model (IV.4), which includes the subsample of CAT bond sponsoring companies with high basis risk. ${ }^{14}$ Altogether, the results from models (IV.1) through (IV.4) provide evidence supporting the basis risk hypothesis (H3) and also align with the theoretical predictions of Doherty and Richter (2002) and Nell and Richter (2004).

\section{Effect of asymmetric information}

This section examines how the presence of information asymmetries influences the use of reinsurance and CAT bonds. Specifically, we inquire whether insurers with fewer long-term reinsurance relationships replace reinsurance with non-indemnity CAT bonds to reduce the negative effects of information asymmetries. The results of this analysis are exhibited in Panel B of Table 7. We divide our sample into two parts based on the magnitude of information asymmetries in insurer-reinsurer relationships, which we measure using Reinsurance Sustainability Index. The sample is divided into two parts at the cross-sectional level based on the median over-time average Reinsurance Sustainability Index among the CAT bond sponsoring insurers. Insurers that exhibit a below-median average Reinsurance Sustainability Index are subject to a high information asymmetry level, whereas insurers with an abovemedian average level are subject to a low information asymmetry level. The regression results for insurers with high information asymmetries are presented in column (V.1) for the full sample and in column (V.2) for the subsample of CAT bond sponsors. Columns (V.3) and (V.4) present the results for insurers with low information asymmetries for the full sample and the subsample of CAT bond sponsors, respectively.

As in our previous analyses we do not measure the substitution effects for indemnity CAT bonds in any of the models in Table 7 . The results for non-indemnity bonds indicate the existence of substitution effects when asymmetric information is high.

\footnotetext{
14 Based on a Wald test, the difference of effect sizes between models (IV.1) and (IV.3) is statistically significant at $p<5 \%$.
} 
According to model (V.1), a 1 percentage point increase of non-indemnity CAT bond use decreases reinsurance use by $1.97(p<0.1 \%)$ percentage points in the full sample. The direction of that effect is identical in the subsample of CAT bond sponsors, where the effect is marginally significant and has a slightly smaller magnitude of $1.52(p<10 \%)$. For insurers with low asymmetric information we observe no substitution effects in models (V.3). However, in model (V.4), that contains only the CAT bond sponsors, the effect is significant and negative. ${ }^{15}$ Therefore, our results in the full sample confirm the asymmetric information hypothesis (H4) and support the theoretical prediction of Finken and Laux (2009) that non-indemnity CAT bonds provide a valuable means of overcoming information asymmetries. This result does not hold in the subsample of CAT bond-sponsoring companies. However, the result presented in column (V.4) should be interpreted with caution, because the relatively high Within- $\mathrm{R}^{2}$ of 0.858 may indicate a high degree of collinearity between the variables in the model.

\section{Interaction effects}

In Table 8, we modify our baseline model by including interaction terms between the CAT bond-specific and the company-specific variables of interest to test hypotheses (H1), (H3) and (H4). Column (VI.1) presents the results for the full sample, whereas column (VI.2) presents the results for the subsample of CAT bond sponsors. Specifically, we include the variables CAT Bond Ratio and Non-Indemnity CAT Bond Ratio as well as the interaction terms CAT Bond Ratio $\times$ Average Reinsurer Rating, Non-Indemnity CAT Bond Ratio $\times$ Geographic HHI and Non-Indemnity CAT Bond Ratio $\times$ Reinsurance Sustainability Index. In both models, the coefficients of the interaction terms are in line with the expectations formulated in hypotheses (H1), (H3), and (H4). More specifically, the negative coefficient of the term CAT Bond Ratio $\times$ Average Reinsurer Rating suggests that the substitution of reinsurance by non-indemnity CAT bonds increases with increasing reinsurer default risk (H1). The positive coefficient of the term Non-Indemnity CAT Bond Ratio $\times$ Geographic $H H I$ suggests that the substitution of reinsurance by non-indemnity CAT bonds decreases with increasing geographic concentration, and thus, increasing exposure to basis risk (H3). The positive coefficient of the term Non-Indemnity CAT Bond Ratio $\times$ Reinsurance Sustainability Index indicates that the substitution of reinsurance by non-indemnity CAT bonds decreases with decreasing information asymmetries (H4). Although not all variables and interaction terms exhibit a statistically significant coefficient, the variables are jointly significant at the level $p<0.1 \%$ in the full sample and at the level $p<5 \%$ in the CAT bond subsample.

Due to the inclusion of the interaction terms, the coefficients have to be interpreted with caution as the baseline effects of the interacted variables also have to be considered when assessing the overall effect. Considering the coefficients and values of the interacted variable, the mean effect size for indemnity bonds is $0.32(0.77)$

\footnotetext{
15 Based on a Wald test, the difference of effect sizes between models (V.2) and (V.4) is statistically insignificant.
} 
Table 8 Influence of CAT bonds on reinsurance use: interaction effects

\begin{tabular}{|c|c|c|}
\hline & $\begin{array}{l}\text { Full sample } \\
\text { (VI.1) }\end{array}$ & $\begin{array}{l}\text { CAT bond sample } \\
\text { (VI.2) }\end{array}$ \\
\hline L.CAT Bond Ratio & $\begin{array}{l}6.76 \\
(5.35)\end{array}$ & $\begin{array}{l}15.01^{\dagger} \\
(7.82)\end{array}$ \\
\hline L.CAT Bond Ratio $\times$ Average Reinsurer Rating & $\begin{array}{l}-2.64 \\
(2.20)\end{array}$ & $\begin{array}{l}-5.82^{\dagger} \\
(3.17)\end{array}$ \\
\hline L.Non-Indemnity CAT Bond Ratio & $\begin{array}{l}-80.11^{\dagger} \\
(45.99)\end{array}$ & $\begin{array}{l}-65.15^{\dagger} \\
(33.55)\end{array}$ \\
\hline L.Non-Indemnity CAT Bond Ratio $\times$ Geographic HHI & $\begin{array}{l}807.14^{\dagger} \\
(468.02)\end{array}$ & $\begin{array}{l}655.78^{\dagger} \\
(346.12)\end{array}$ \\
\hline L.Non-Indemnity CAT Bond Ratio $\times$ Reinsurance Sust. Index & $\begin{array}{l}25.74 \\
(19.61)\end{array}$ & $\begin{array}{l}21.59 \\
(15.77)\end{array}$ \\
\hline Average Reinsurer Rating & $\begin{array}{l}0.42^{\dagger} \\
(0.25)\end{array}$ & $\begin{array}{l}3.75^{*} \\
(1.60)\end{array}$ \\
\hline Missing Rating Information & $\begin{array}{l}-0.55 \\
(1.01)\end{array}$ & $\begin{array}{l}0.33 \\
(2.65)\end{array}$ \\
\hline Basis Risk & $\begin{array}{l}-0.33 \\
(0.73)\end{array}$ & $\begin{array}{l}-5.45 \\
(4.95)\end{array}$ \\
\hline Reinsurance Sustainability Index & $\begin{array}{l}-1.27 * * \\
(0.47)\end{array}$ & $\begin{array}{l}-11.77 * * * \\
(3.19)\end{array}$ \\
\hline Year fixed effects & Yes & Yes \\
\hline Company-specific controls & Yes & Yes \\
\hline Observations & 11,545 & 357 \\
\hline Within- $R^{2}$ & 0.056 & 0.503 \\
\hline Adjusted within- $R^{2}$ & 0.052 & 0.435 \\
\hline
\end{tabular}

This table reports fixed effects estimates of company- and CAT bond-specific variables on the Reinsurance Ratio including interaction terms between the CAT bond-specific variables CAT Bond Ratio and NonIndemnity CAT Bond Ratio and the variables Average Reinsurer Rating, Geographic HHI, and Reinsurance Sustainability Index. Column (VI.1) presents the results for the entire sample, whereas column (VI.2) presents the results for the subsample of companies that sponsor a CAT bond at least once over the sample period. Company-specific control variables are the same as in models (I.1) to (I.4). Standard errors, which are shown in parentheses, are clustered at the company level and robust to heteroscedasticity. The symbols $\dagger, *, * *$, and $* * *$ indicate statistical significance at the $10 \%, 5 \%, 1 \%$ and $0.1 \%$ levels, respectively

in the full sample (in the CAT bond subsample). Thus, as in the prior regression models, we do not measure a substitution effect from indemnity bonds. For nonindemnity bonds, the mean effect size is $-1.10(-0.80)$ in the full sample (in the CAT bond subsample), which indicates the existence of a substitution effect. A one standard deviation change of the respective company-specific variable at the mean level of non-indemnity CAT bond use would have the following effects on reinsurance use in the full sample (in the CAT bond subsample):

- Average Reinsurer Rating: - 0.40 (0.25)

- Geographic HHI: - 6.24 (- 5.16)

- Reinsurance Sustainability Index: - 1.25 (0.82)

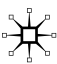


This result implies that substitution follows our hypotheses except for the variables Average Reinsurer Rating and Reinsurance Sustainability Index in the CAT bond subsample. However, in those subsamples, the observed positive effect is a consequence of both deteriorating average reinsurer ratings and decreasing sustainability of reinsurance relationships triggering higher reinsurance demand. The CAT bondrelated interaction terms partially offset that effect. Altogether, the analysis of interaction effects therefore supports the hypotheses (H1), (H3) and (H4).

\section{Dynamic model}

In this section we consider an alternative regression model to estimate the effect of CAT bond use on reinsurance use. Given that reinsurance is based on long-term relationships between insurers and reinsurers, it is plausible that the level of reinsurance use exhibits a certain degree of persistence over time. Consequently, we use the following dynamic model of reinsurance use:

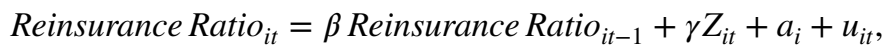

for insurers $i=1, \ldots, n$ and points in time $t=1, \ldots, T$. The model is similar to the model in Equation (4), ${ }^{16}$ which we estimate with fixed effects. The difference between the models is the inclusion of a lagged dependent variable in Equation (5), which characterises the dynamic development of the Reinsurance Ratio that may be influenced by its past realisations (Arellano and Bond 1991; Arellano and Bover 1995; Blundell and Bond 1998). The model in Equation (5) cannot be estimated by OLS, because the fixed effects $a_{i}$ in the error term are correlated with the lagged dependent variable Reinsurance Ratio ${ }_{i t-1}$, which gives rise to a 'dynamic panel bias' (Nickell 1981; Blundell and Bond 1998; Roodman 2009b). The dynamic panel bias cannot be eliminated by fixed effects estimation either, because after the within transformation, the lagged dependent variable Reinsurance Ratio ${ }_{i t-1}$ is negatively correlated with $u_{i t-1}$, which forms part of the within transformation of the error term $u_{i t}$. Therefore, we estimate our dynamic model with the GMM. The above model is estimated with the two-step system GMM estimator introduced by (Blundell and Bond 1998). ${ }^{17}$

\footnotetext{
${ }^{16}$ For simplification, the year-fixed effects and other explanatory variables are summarised in $Z_{i t}$.

17 The system GMM estimator is based on the assumptions of (1) no serial correlation in the error term $u_{i t}$, (2) explanatory variables are uncorrelated with future realisations of the error term and (3), the fixed effects $a_{i}$ are uncorrelated with the first difference of the explanatory variables (Blundell and Bond 1998). Based on these assumptions, the following moment conditions can be applied for the system GMM estimator:
}

$$
\begin{aligned}
& \sum_{i} \text { Reinsurance Ratio }_{i t-s}\left(u_{i t}-u_{i t-1}\right)=0 \quad \text { for } s \geqslant 2 ; t=3, \ldots T, \\
& \sum_{i} Z_{i t-s}\left(u_{i t}-u_{i t-1}\right)=0 \quad \text { for } s \geqslant 2 ; t=3, \ldots T, \\
& \sum_{i}\left(\text { Reinsurance Ratio }_{i t-1}-\text { Reinsurance Ratio }_{i t-2}\right)\left(a_{i}+u_{i t}\right)=0 \text { for } t=3, \ldots T \text {, } \\
& \sum_{i}\left(Z_{i t-1}-Z_{i t-2}\right)\left(a_{i}+u_{i t}\right)=0 \quad \text { for } \quad t=3, \ldots T .
\end{aligned}
$$


Based on the recommendations of the literature and the specificity of our analysis, we apply the following principles in our GMM estimation procedure. We instrument the lagged dependent variable, which we consider predetermined, that means, independent of current disturbances but dependent on past disturbances, with its first lag, and the CAT bond-related variables, which we consider endogenous in this setting, with their second lag (Roodman 2009b). We do not include longer lags to instrument predetermined or endogenous model variables in order to restrict the problems related with too large sets of instruments (Roodman 2009a, b). We further collapse the moment conditions as suggested by Roodman (2009a, b), which means that the moment conditions in Equation (6) are not formed for each time period separately, but by summing over all time periods. We further use the Hansen test to assess the overall validity of instruments used in our models and the Difference-in-Hansen test to examine the validity of the individual instruments in our model (Blundell and Bond 1998; Roodman 2009a, b). ${ }^{18}$ Initially, we treat all variables other than the lagged dependent variable and the CAT bond-related variables as exogenous. If the Difference-in-Hansen test suggests otherwise, we instrument the respective variable by its lag. ${ }^{19}$ We further use the Arellano-Bond test on auto-correlation of the disturbances to identify second order auto-correlation of the differenced disturbances $u_{i t}$, which is critical as it would invalidate the used instruments (Arellano and Bond 1991; Roodman 2009a, b).

Table 9 shows the results obtained with the dynamic model. Columns (VII.1) and (VII.2) present the analysis of reinsurer default risk. Column (VII.3) shows the effect of the risk layer. Basis risk is analysed in columns (VII.4) and (VII.5). The asymmetric information hypothesis is tested in models (VII.6) and (VII.7). All results refer to the full sample. The dynamic model largely confirms the results from our previous analyses. The test statistic of the $\chi^{2}$-Hansen test is insignificant in all the considered models, which supports the validity of the used instruments. Most of the models indicate a significant but relatively small degree of persistence in the reinsurance ratio. In column (VII.2), CAT bond use has a significant negative effect $(p<0.1 \%)$ on reinsurance use, which supports the reinsurer default risk hypothesis. This effect is not present among the sample with low reinsurer default risk (column (VII.1)). In column (VII.3), the use of non-indemnity CAT bonds has a significant negative effect on reinsurance use both in high- and low-risk layers, which indicates a substitution effect between reinsurance and CAT bonds, but is contrary to the risk layer hypothesis (H2), suggesting that substitution stems from high-risk layers (Nell and Richter 2004). Consequently, we further examine this unexpected result in Section $\mathrm{H}$ of the Online Appendix and observe that it is caused by the insurer Allianz Insurance Group by significantly reducing its cession of reinsurance in the context of a restructering of its reinsurance programme in the years 2013 and 2014 (Konzern 2014). When we exclude observations related to Allianz Insurance Group during

\footnotetext{
18 We also report the result of a Sargan test on instrument validity, but base our assessment of the model on the Hansen test, because the Sargan test is not robust to heteroscedasticity (Roodman 2009a, b).

19 We use the first lag for predetermined variables and the second lag for endogenous variables (Roodman 2009b).
} 


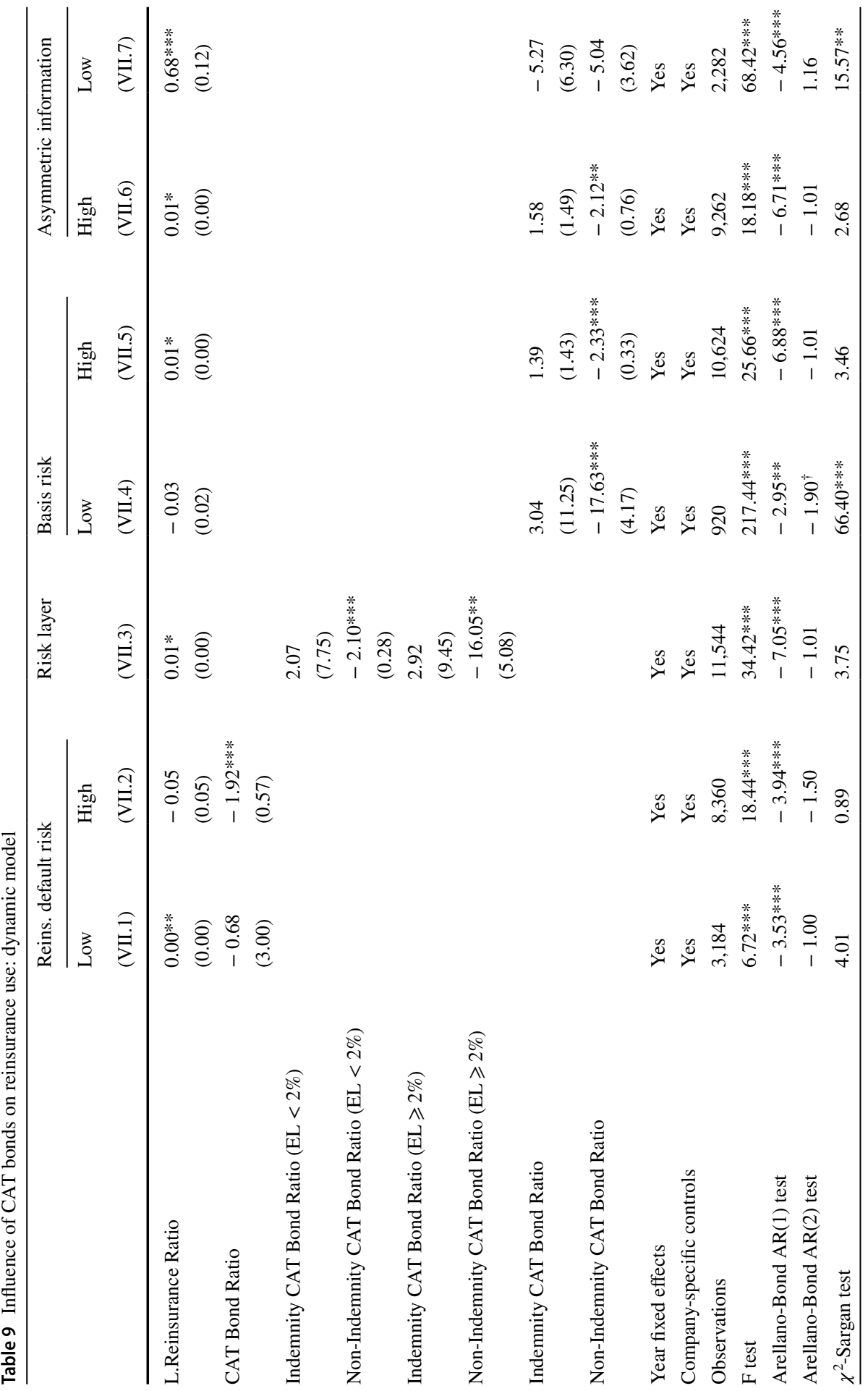

赵- 


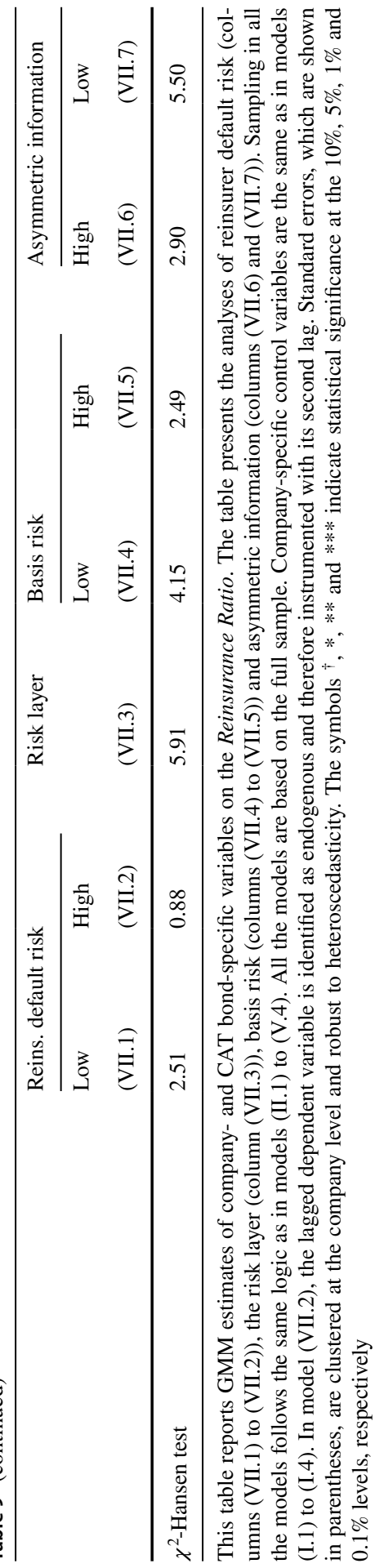

站。 
the mentioned years, the coefficient of Non-Indemnity CAT Bond Ratio (EL $2 \%$ ) is no longer significant, and thus, the risk layer hypothesis $(\mathrm{H} 2)$ is supported. The coefficient for indemnity CAT bonds, is insignificant, suggesting that those are rather used complementary to reinsurance. The basis risk hypothesis (H3) is confirmed by the dynamic model, because the negative coefficient of the Non-Indemnity CAT Bond Ratio is significantly larger in the subsample of companies with low basis risk (based on a $99.9 \%$ confidence interval). Under high asymmetric information (H4), reinsurance is substituted with non-indemnity CAT bonds.

\section{Conclusions}

This study examines the use of reinsurance and CAT bonds in insurers' corporate risk management strategies and empirically investigates if and under which circumstances CAT bonds add value to them. Four hypotheses are tested based on the theoretical literature. Our reinsurer default risk hypothesis (H1), which suggests that CAT bonds are valuable for insurers with high reinsurer default risk, is supported by the majority of our analyses. In the risk layer hypothesis (H2) we assumed that CAT bonds substitute for reinsurance in high-risk layers. Our results largely support that hypothesis. The basis risk hypothesis $(\mathrm{H} 3)$, which proposes that insurers with a low exposure to basis risk replace reinsurance with non-indemnity CAT bonds, is supported by all our analyses. We obtain ambiguous evidence with respect to the asymmetric information hypothesis ( $\mathrm{H} 4)$, which conjectures that a high level of asymmetric information in insurer-reinsurer relationships causes substitution between reinsurance and non-indemnity CAT bonds in order to overcome these information asymmetries. Finally, our analyses indicate that the substitution of reinsurance by CAT bonds is more strongly influenced by non-indemnity CAT bonds.

We are the first to empirically investigate the circumstances under which CAT bonds add value to insurers' risk management strategies. The insights provided by our study are of both theoretical and practical relevance. We extend the existing evidence that companies' risk management instruments are not chosen arbitrarily (Haushalter 2000; Graham and Rogers 2002; Adam et al. 2007) but are, rather, a consequence of a careful decision process to the CAT bond market. We also confirm the theoretical literature's conclusions regarding the added value provided by CAT bonds, which consists of reducing reinsurer default risk and introducing basis risk (Doherty and Richter 2002; Nell and Richter 2004; Cummins and Trainar 2009; Finken and Laux 2009; Lakdawalla and Zanjani 2012; Trottier and Lai 2017; Subramanian and Wang 2018). By revealing that the use of reinsurance and CAT bonds is dependent on bond-, company- and market-specific factors, we offer insights that are important from a regulator perspective. Information on the most important determinants of reinsurance and CAT bond use may be valuable for regulators seeking to motivate insurers to diversify their toolbox of risk management instruments or to incentivise a greater overall use of risk management instruments. Similarly, our results may be insightful for re/insurance and CAT bond market participants in order to better understand the choices of different risk management instruments. Finally, our results enrich the possible explanations for the still-limited size of CAT bond markets compared to traditional reinsurance markets 
(Hagendorff et al. 2014; Braun 2016). We observe that factors such as a high basis risk in insurer-reinsurer relationships reduce the relative attractiveness of CAT bonds. It is thus plausible that, for a large share of insurance companies in our sample, CAT bonds are less advantageous as a risk transfer instrument than traditional reinsurance.

Supplementary Information The online version contains supplementary material available at https://doi. org/10.1057/s41288-021-00234-6.

Acknowledgements We thank two anonymous referees and our colleagues at the Department of Finance at Braunschweig Institute of Technology for their productive remarks on this article.

Funding Open Access funding enabled and organised by Projekt DEAL.

Open Access This article is licensed under a Creative Commons Attribution 4.0 International License, which permits use, sharing, adaptation, distribution and reproduction in any medium or format, as long as you give appropriate credit to the original author(s) and the source, provide a link to the Creative Commons licence, and indicate if changes were made. The images or other third party material in this article are included in the article's Creative Commons licence, unless indicated otherwise in a credit line to the material. If material is not included in the article's Creative Commons licence and your intended use is not permitted by statutory regulation or exceeds the permitted use, you will need to obtain permission directly from the copyright holder. To view a copy of this licence, visit http://creativecommons.org/licen ses/by/4.0/.

\section{References}

Adam, T., S. Dasgupta, and S. Titman. 2007. Financial constraints, competition, and hedging in industry equilibrium. The Journal of Finance 62 (5): 2445-2473.

Allianz Konzern. 2014. Geschäftsbericht 2013. Munchen: Allianz Konzern.

Altuntas, M., J. Garven, and J. Rauch. 2018. On the corporate demand for insurance: Evidence from the global reinsurance market. Risk Management and Insurance Review 21 (2): 211-242.

Arellano, M., and S. Bond. 1991. Some tests of specification for panel data: Monte Carlo evidence and an application to employment equations. The Review of Economic Studies 58 (2): 277-297.

Arellano, M., and O. Bover. 1995. Another look at the instrumental variable estimation of error-components models. Journal of Econometrics 68 (1): 29-51.

Artemis. 2020. Catastrophe bonds \& ILS issued and outstanding by year.

Ashby, S.G., and S.R. Diacon. 1998. The corporate demand for insurance: A strategic perspective. The Geneva Papers on Risk and Insurance-Issues and Practice 23 (1): 34-51.

Baltagi, B.H. 2013. Econometric Analysis of Panel Data. 5th ed. Hoboken: Wiley.

Bernard, C., and M. Ludkovski. 2012. Impact of counterparty risk on the reinsurance market. North American Actuarial Journal 16 (1): 87-111.

Berry-Stölzle, T.R., A.P. Liebenberg, J.S. Ruhland, and D.W. Sommer. 2012. Determinants of corporate diversification: Evidence from the property-liability insurance industry. Journal of Risk and Insurance 79 (2): $381-413$.

Bevere, L., A. Ehrler, V. Kuma, R. Lechner, A. Schelbert, M. Schwartz, and R. Sharan. 2019. Natur- und Manmade Katastrophen im Jahr 2018: Sekundäre Naturgefahren auf dem Vormarsch. Technical report, Swiss Re.

Biener, C., M. Eling, and J.H. Wirfs. 2016. The determinants of efficiency and productivity in the Swiss insurance industry. European Journal of Operational Research 248 (2): 703-714.

Blundell, R., and S. Bond. 1998. Initial conditions and moment restrictions in dynamic panel data models. Journal of Econometrics 87 (1): 115-143.

Braun, A. 2016. Pricing in the primary market for cat bonds: New empirical evidence. Journal of Risk and Insurance 83 (4): 811-847. 
Cai, J., Y. Fang, Z. Li, and G.E. Willmot. 2013. Optimal reciprocal reinsurance treaties under the joint survival probability and the joint profitable probability. Journal of Risk and Insurance 80 (1): 145-168.

Carayannopoulos, P., and M.F. Perez. 2015. Diversification through catastrophe bonds: Lessons from the subprime financial crisis. The Geneva Papers on Risk and Insurance-Issues and Practice 40 (1): 1-28.

Chen, H., J.D. Cummins, S. Tao, and M.A. Weiss. 2018. The reinsurance network among U.S. property-casualty insurers: Microstrucutre, insolvency risk, and contagion. Journal of Risk and Insurance 87 (2): 253-284.

Chen, X., H. Doerpinghaus, B.-X. Lin, and T. Yu. 2008. Catastrophic losses and insurer profitability: Evidence from 9/11. Journal of Risk and Insurance 75 (1): 39-62.

Choi, B.P., and M.A. Weiss. 2005. An empirical investigation of market structure, efficiency, and performance in property-liability insurance. Journal of Risk and Insurance 72 (4): 635-673.

Cole, C.R., E. He, K.A. McCullough, A. Semykina, and D.W. Sommer. 2011. An empirical examination of stakeholder groups as monitoring sources in corporate governance. Journal of Risk and Insurance 78 (3): 703-730.

Cole, C.R., R.B. Lee, and K.A. McCullough. 2007. A test of the eclectic paradigm: Evidence from the US reinsurance market. Journal of Risk and Insurance 74 (2): 493-522.

Cole, C.R., and K.A. McCullough. 2006. A reexamination of the corporate demand for reinsurance. Journal of Risk and Insurance 73 (1): 169-192.

Cummins, J., D. Lalonde, and R. Phillips. 2004. The basis risk of catastrophic-loss index securities. Journal of Financial Economics 71 (1): 77-111.

Cummins, J., and P. Trainar. 2009. Securitization, insurance, and reinsurance. Journal of Risk and Insurance 76 (3): 463-492.

Cummins, J., and M. Weiss. 2009. Convergence of insurance and financial markets: Hybrid and securitized risk-transfer solutions. Journal of Risk and Insurance 76 (3): 493-545.

Cummins, J.D., and G.P. Nini. 2002. Optimal capital utilization by financial firms: Evidence from the property-liability insurance industry. Journal of Financial Services Research 21 (1-2): 15-53.

Cummins, J.D., R.D. Phillips, and S.D. Smith. 2001. Derivatives and corporate risk management: Participation and volume decisions in the insurance industry. Journal of Risk and Insurance 68 (1): 51-91.

Desjardins, D., and G. Dionne. 2017. Reinsurance demand and liquidity creation. Working Papaer, HEC Montreal.

Doherty, N. 1997. Innovations in managing catastrophe risk. Journal of Risk and Insurance 64 (4): 713-718.

Doherty, N., and A. Richter. 2002. Moral hazard, basis risk, and gap insurance. Journal of Risk and Insurance 69 (1): 9-24.

Doherty, N.A., and H. Schlesinger. 1983. Optimal insurance in incomplete markets. Journal of Political Economy 91 (6): 1045-1054.

Finken, S., and C. Laux. 2009. Catastrophe bonds and reinsurance: The competitive effect of information-insensitive triggers. Journal of Risk and Insurance 76 (3): 579-605.

Froot, K. 2001. The market for catastrophe risk: a clinical examination. Journal of Financial Economics 60 (2-3): 529-571.

Froot, K.A., D.S. Scharfstein, and J.C. Stein. 1993. Risk management: Coordinating corporate investment and financing policies. The Journal of Finance 48 (5): 1629-1658.

Garven, J.R., J.I. Hilliard, and M.F. Grace. 2014. Adverse selection in reinsurance markets. The Geneva Risk and Insurance Review 39 (2): 222-253.

Garven, J.R., and J. Lamm-Tennant. 2003. The demand for reinsurance: Theory and empirical tests. Insurance and Risk Management 7 (3): 217-237.

Götze, T., and M. Gürtler. 2020. Hard markets, hard times: On the inefficiency of the CAT bond market. Journal of Corporate Finance. https://doi.org/10.1016/j.jcorpfin.2019.101553.

Graham, J.R., and D.A. Rogers. 2002. Do firms hedge in response to tax incentives? The Journal of Finance 57 (2): 815-839.

Gürtler, M., M. Hibbeln, and C. Winkelvos. 2016. The impact of the financial crisis and natural catastrophes on CAT bonds. Journal of Risk and Insurance 83 (3): 579-612.

Hagendorff, B., J. Hagendorff, K. Keasey, and A. Gonzalez. 2014. The risk implications of insurance securitization: The case of catastrophe bonds. Journal of Corporate Finance 25: 387-402.

Haushalter, G.D. 2000. Financing policy, basis risk, and corporate hedging: Evidence from oil and gas producers. The Journal of Finance 55 (1): 107-152.

Jean-Baptiste, E.L., and A.M. Santomero. 2000. The design of private reinsurance contracts. Journal of Financial Intermediation 9 (3): 274-297. 
Jung, H.W.H., Z.J. Liu, and N. Zhu. 2018. Product market competition and corporate demand for insurance. Working Paper, University of Melbourne.

Lakdawalla, D., and G. Zanjani. 2012. Catastrophe bonds, reinsurance, and the optimal collateralization of risk-transfer. The Journal of Risk and Insurance 79 (2): 449-476.

Lee, H.-H., and C.-Y. Lee. 2012. An analysis of reinsurance and firm performance: Evidence from the Taiwan property-liability insurance industry. The Geneva Papers on Risk and Insurance-Issues and Practice 37 (3): 467-484.

Lin, Y., J. Yu, and M.O. Peterson. 2015. Reinsurance networks and their impact on reinsurance decisions: Theory and empirical evidence. Journal of Risk and Insurance 82 (3): 531-569.

Mankaï, S., and A. Belgacem. 2016. Interactions between risk taking, capital, and reinsurance for property-liability insurance firms. Journal of Risk and Insurance 83 (4): 1007-1043.

Mayers, D., and C.W. Smith Jr. 1990. On the corporate demand for insurance: Evidence from the reinsurance market. Journal of Business 63: 19-40.

Modigliani, F., and M.H. Miller. 1958. The cost of capital, corporation finance and the theory of investment. The American Economic Review 48 (3): 261-297.

National Association of Insurance Commissioners. 2018. Insurance Regulatory Information System (IRIS) Ratios Manual.

Nell, M., and A. Richter. 2004. Improving risk allocation through indexed cat bonds. The Geneva Papers on Risk and Insurance-Issues and Practice 29 (2): 183-201.

Nickell, S. 1981. Biases in dynamic models with fixed effects. Econometrica: Journal of the Econometric Society 49 (6): 1417-1426.

Park, S.C., X. Xie, and P. Rui. 2019. The sensitivity of reinsurance demand to counterparty risk: Evidence from the US property-liability insurance industry. Journal of Risk and Insurance 86 (4): 915-946.

Powell, L.S., and D.W. Sommer. 2007. Internal versus external capital markets in the insurance industry: The role of reinsurance. Journal of Financial Services Research 31 (2-3): 173-188.

Regan, L., and Y. Hur. 2007. On the corporate demand for insurance: The case of KOREAN nonfinancial firms. Journal of Risk and Insurance 74 (4): 829-850.

Roodman, D. 2009a. A note on the theme of too many instruments. Oxford Bulletin of Economics and statistics 71 (1): 135-158.

Roodman, D. 2009b. How to do xtabond2: An introduction to difference and system GMM in Stata. The Stata Journal 9 (1): 86-136.

Shiu, Y.-M. 2011. Reinsurance and capital structure: Evidence from the United Kingdom non-life insurance industry. Journal of Risk and Insurance 78 (2): 475-494.

Standard \& Poor's. 2020. Global Reinsurance Highlights 2020. New York City: Standard \& Poor's Financial Services LLC.

Subramanian, A., and J. Wang. 2018. Reinsurance versus securitization of catastrophe risk. Insurance: Mathematics and Economics 82: 55-72.

Trottier, D.-A., and V.S. Lai. 2017. Reinsurance or CAT bond? How to optimally combine both. The Journal of Fixed Income 27 (2): 65-87.

Wang, J.L., V.Y. Chang, G.C. Lai, and L.Y. Tzeng. 2008. Demutualization and demand for reinsurance. The Geneva Papers on Risk and Insurance-Issues and Practice 33 (3): 566-584.

Wooldridge, J.M. 2015. Introductory Econometrics: A Modern Approach. Boston: Nelson Education.

Yanase, N., and P. Limpaphayom. 2017. Organization structure and corporate demand for reinsurance: The case of the Japanese Keiretsu. Journal of Risk and Insurance 84 (2): 599-629.

Zou, H., M.B. Adams, and M.J. Buckle. 2003. Corporate risks and property insurance: Evidence from the People's Republic of China. Journal of Risk and Insurance 70 (2): 289-314.

Publisher's Note Springer Nature remains neutral with regard to jurisdictional claims in published maps and institutional affiliations. 


\section{About the authors}

Tobias Götze graduated with a Masters in industrial engineering from Braunschweig Institute of Technology, Germany, in 2014. Afterwards, he joined the Department of Finance at Braunschweig Institute of Technology, as a Ph.D. candidate and research assistant. He received his Ph.D. degree from Braunschweig Institute of Technology in 2021. Since 2020, he has been working with the reinsurer Hannover Re. His research activities are focused on the transfer of catastrophic risks to the capital market and the pricing of catastrophe bonds.

Marc Gürtler graduated in mathematics from the University of Cologne, Germany, in 1992. Subsequently, he worked as a risk manager at AXA Colonia Insurance Company. In 1995, he joined the Department of Business Administration at the University of Bonn, Germany, as a Ph.D. candidate and research assistant. He received his Ph.D. degree from the University of Bonn in 1997. From 1997 to 2002, he was an Assistant Professor in the Departments of Business Administration at the University of Bonn and at RWTH Aachen University. He received a habilitation degree in Business Administration from RWTH Aachen University in 2002. Since 2002, he has been a full Professor of Finance at Braunschweig Institute of Technology. His research interests are focused on the pricing of risk transfer instruments and different types of labour market signaling. 